\title{
Capacidade Tecnológica e Inovação em Organizações de Serviços Intensivos em Conhecimento: evidências de institutos de pesquisa em Tecnologias da Informação e da Comunicação (TICs) no Brasil*
}

\section{Paulo N. Figueiredo}

Professor da EBAPE/FGV. Pesquisador-chefe do Programa de Pesquisa em

Gestão da Aprendizagem Tecnológica e Inovação Industrial no Brasil, da EBAPE/FGV

\section{RESUMO}

Embora existam vários estudos sobre estratégias de inovação na indústria de tecnologias de informação e comunicação (TICs), há uma escassez de estudos sobre o grau de capacidade tecnológica em nível de organizaçōes que operam à base de TICs, no contexto de áreas em desenvolvimento. Este artigo examina tipos e níveis de capacidades tecnológicas em uma amostra de 18 dos principais institutos de pesquisa em TICs no Brasil, aqui denominados de organizações de serviços intensivas em conhecimento (OSICS). O artigo baseia-se em evidências empíricas de primeira-mão coletadas com base em extensivo trabalho de campo. O estudo encontrou uma variedade de níveis de capacidades para funçôes

\footnotetext{
Este artigo deriva de projeto de pesquisa implementado no âmbito do Programa de Pesquisa em Gestão da Aprendizagem Tecnológica e Inovação Industrial no Brasil, da Escola Brasileira de Administração Pública e de Empresas (EBAPE), da Fundação Getúlio Vargas (FGV). Agradeço à EBAPE/FGV pelo valioso suporte à implementação deste estudo. Sou grato a Luciana Marins e Roberta Michel que, de forma diferenciada, contribuíram com seu trabalho de assistência a este projeto de pesquisa. Expresso meu agradecimento especial aos diretores, gerentes, engenheiros e técnicos das organizações que participaram do trabalho de campo desta pesquisa pelo seu tempo, atenção e paciência em responder às perguntas e mostrar suas instalações. Sem a generosidade deles, a pesquisa subjacente a este artigo não teria sido materializada. Agradeço também aos dois avaliadores anônimos da Revista Brasileira de Inovação pelos seus comentários críticos, detalhados e extremamente úteis. Quaisquer erros e/ou omissões são de minha inteira responsabilidade.
} 
tecnológicas específicas, não apenas entre as organizações da amostra, mas também dentro delas. Foi encontrada uma diversidade de processos intraorganizacionais de aprendizagem e de ligaçôes com as demais organizaçôes do sistema de inovação, examinadas aqui como fonte de capacidade tecnológica. Ao aplicar métricas que captam nuanças de tipos e níveis de capacidades tecnológicas e de suas fontes, este artigo contribui para oferecer uma perspectiva mais realista sobre a inovação no âmbito de uma parte específica do seu setor das TICs no Brasil. Pelo menos no âmbito desta amostra estudada, e considerando as limitações deste estudo, as evidências apontam para uma resposta positiva desses institutos ao arcabouço institucional de incentivo às atividades inovadoras criado no início dos anos 1990 (a nova Lei de Informática). Tais evidências, por sua vez, são importantes para clarificar e apoiar o desenho e a implementação de estratégias para acelerar inovação e fortalecer a competitividade deste setor no Brasil.

Palavras-Chave | Capacidade Tecnológica; Tecnologias da Informação e da Comunicação (TICs); Organizações de Serviços Intensivas em Conhecimento (OSICs); Inovação Industrial

Códigos JEL | O14, O32, O38

\section{ABSTRACT}

Although there are several studies of innovation in the information and communication (ICT) industry, there still is a scarcity of studies on organisationlevel technological capability in the ICTs sector in the context of late-industrialisation. This article examines types and levels of technological capability in a sample of 18 ICTs institutes in Brazil that are studied here as knowledge-intensive business services (KIBS). The article draws on first-hand empirical evidence gathered on the basis of extensive fieldwork. The study found a variety of capabilities for specific technological functions, not only across the sampled organisations, but also within them. It also found a diversity of intra-organization learning processes and inter-organisational links with other innovation system organisations. These were examined here as key sources of technological capabilities. By applying metrics that capture nuances of types and levels of technological capabilities and their key sources, this study offers a realistic perspective on innovation in a relevant 
part of the ICT industry in Brazil. At least within the context of this sample, and considering the limitations of this study, the evidence here points out to a positive response from these institutes to the incentive regime that was set up during the early-1990s (the new ICT Law). Such evidence, in turn, is important to clarify and support the design and implementation of strategies to speed up innovation and strengthen the competitiveness of this industrial sector in Brazil.

KeYwords | Technological Capability; Information and Communication Technologies (ICTs); Knowledge-intensive Business Services (KIBS); Industrial Innovation

JEL-Codes $\quad$ O14, O32, O38

\section{Introdução}

Como argumentado por Keith Pavitt, as alterações na direção da mudança tecnológica ao longo dos últimos 30 anos têm se caracterizado por uma progressiva desintegração de atividades de projeto (design) de produtos e serviços das atividades de produção. Uma das causas dessa mudança é a aplicação de melhorias em Tecnologias da Informação e da Comunicação (TICs). A TIC tem facilitado o intercâmbio de informação e conhecimento codificado dos designers para a manufatura. Isto, por sua vez, é conseqüência do processo de codificação que se iniciou há cerca de 25 anos, quando as empresas começaram a instalar seus sistemas integrados de Tecnologia de Informação (TI). Como resultado, as atividades de desenho e Pesquisa e Desenvolvimento ( $P \& D$ ) permaneceriam em países tecnologicamente avançados, principalmente TIC e suas aplicações, ou seja, as atividades inovadoras em serviços, enquanto que países em desenvolvimento estariam confinados às atividades de manufatura (ver Pavitt, 2002). 
Por outro lado, Miles (2003) argumenta que a economia baseada no conhecimento apresenta duas características-chave que têm se intensificado especialmente após os anos 1960: (i) a crescente relevância da indústria de serviços nas atividades econômicas e (b) a crescente importância das organizações de serviços intensivos em conhecimento (OSICs). ${ }^{1}$ Tais organizaçôes operam à base da provisão de serviços tradicionais (por exemplo, contabilidade e serviços jurídicos), mas, principalmente os serviços fortemente baseados em conhecimento técnico-científico (por exemplo, as várias atividades baseadas em design, gestão de projetos e engenharia e aquelas fortemente baseadas em TIC, como é o caso do desenvolvimento de software). Por meio de atividades inovadoras em TICs, as OSICs têm servido de apoio a diversas atividades econômicas (Barras, 1986; Miles, 2003). Outra implicação é que as TICs podem contribuir para a difusão de atividades tecnológicas inovadoras (Dosi, 1988; Castells, 1996; Pavitt \& Steinmueller, 2001).

Porém, essas duas perspectivas consideram a intensificação das atividades inovadoras em serviços apenas no contexto de países tecnologicamente avançados. Muito pouco é considerado em termos do engajamento de organizaçôes de países em desenvolvimento em atividades inovadoras, a partir da TIC, na indústria de serviços, embora haja uma vasta literatura produzida sobre este tema ao longo das últimas décadas, tanto em nível conceitual como no plano empírico a partir da experiência de vários países em desenvolvimento, incluindo o Brasil (Freeman \& Perez, 1988; Baptista, 1988; Cooper \& Kaplinsky, 1989; Tigre, 1988, 1993; Ernst \& O’Connor 1989; Mody \& Dahlman, 1992; Gaio, 1992; Cassiolato, 1992; Carvalho, 1992; Hobday, 1995).

Por isso, não obstante a existência de vários estudos sobre inovação na indústria de serviços, sob a perspectiva da economia do conhecimento, das capacidades dinâmicas e da competição globalizada, a grande maioria dos estudos ainda restringe-se a examinar a inovação em serviços em economias tecnologicamente avançadas como Estados Unidos, Reino Unido e Alemanha (ver, por exemplo, as experiências examinadas em Tidd \& Hull, 2003).

Ocorre que por meio das TICs, certas economias em desenvolvimento têm conseguido construir capacidades tecnológicas inovadoras e alcançar performance internacionalmente competitiva em áreas importantes da indústria

${ }^{1}$ Trata-se de nossa tradução da expressão knowledge-intensive business services (KIBS) usada em Miles (2003). 
de serviços, como é o caso da indústria de software (ver Ethiraj et al., 2005, sobre a experiência da indústria de software na Índia). Porém, há uma escassez de estudos recentes sobre o processo de construção de capacidade tecnológica aprendizagem tecnológica - em atividades de serviços em países em desenvolvimento, especialmente em nível de organizações.

Por outro lado, há sinais claros de que empresas transnacionais têm buscado intensificar a alocação de suas atividades de serviços intensivos em conhecimento - tais como diversos tipos de atividades de P\&D - em países em desenvolvimento. Alguns países são receptores potenciais de tais investimentos como é o caso de Brasil, Rússia, Índia, China, África do Sul e Leste Europeu. Por exemplo, estudos recentes divulgados pelo The Economist Intelligence Unit e pela United Conference on Trade and Development (UNCTAD) (The Economist Intelligence Unit, 2004; UNCTAD, 2005), colocam o Brasil em posição competitiva frente a outros países no que diz respeito à atração de atividades tecnológicas inovadoras. Segundo esses dois estudos, um dos fatores-chave para a atração de atividades tecnológicas inovadoras é a existência e a qualidade de organizações capazes de apoiar, por meio, por exemplo, da formação de recursos humanos adequadamente qualificados e de atividades conjunta de $\mathrm{P} \& \mathrm{D}$ tais como, universidades, institutos de pesquisa públicos e empresariais, escolas técnicas e centros vocacionais, laboratórios de ensaios diversos e de metrologia, entre outras. ${ }^{2}$

Tais organizações constituem um apoio vital para o desenvolvimento tecnológico em indústrias nas quais há um crescente processo de desintegração em níveis interorganizacional e internacional - entre as atividades de projeto (design) e produção, como é o caso da indústria de software (Pavitt \& Steinmueller, 2001; Pavitt, 2002). Porém, é justamente a construção e o fortalecimento dessas organizações de apoio ao sistema de inovação que, historicamente, tem sido um dos maiores desafios ao processo de desenvolvimento tecnológico e crescimento industrial em economias de industrialização tardia (Gerschenkron, 1962; Freeman, 1982; Bell, 1993; von Tunzelmann, 1997; Bell \& Albu, 1999; Kuruvilla et al., 2002).

\footnotetext{
2 Com as empresas, este conjunto de organizações e também de instituições (por exemplo, leis, normas demais mecanismos institucionais - "regras do jogo") constituem o "sistema nacional de inovação". Tal definição, por sua vez, alinha-se à "perspectiva sistêmica" sobre inovação (ver Lundvall, 1992; Nelson, 1992, Edquist, 1997), a qual será apresentada na Seção 2.
} 
Assim como em outros países em desenvolvimento, no Brasil, as reformas estruturais adotadas a partir do final da década de 1980 e início dos anos 1990 formalizaram o fim do regime industrial protecionista associado à implementação da política de substituição de importações desde os anos 1950. Tais reformas marcaram a transição para um regime industrial à base de liberalização comercial e de um sistemático processo de privatização a fim de vender grandes empresas estatais. A privatização fazia parte de um programa de longo prazo baseado em um processo de liberalização conducente às novas condiçōes em que as empresas começariam a operar (BNDES, 1994; Saravia, 1996; Suzigan \& Villela, 1997).

Em abril de 1990, formalizou-se uma política industrial cujo objetivo anunciado era o de preparar a economia brasileira para competição globalizada. Composta de vários programas, a Política Industrial e de Comércio Exterior (PICE) buscava incentivar o desenvolvimento da capacidade tecnológica industrial. Tais programas previam igualmente incentivos fiscais e creditícios. Em particular, o Programa Brasileiro de Qualidade e Produtividade (PBQP) consistia: (a) em subprogramas para difundir novas técnicas de gestão e organização da produção (por exemplo, C/GQT, JIT) nas indústrias; e (b) na criação de instituições (por exemplo, o Código de Defesa do Consumidor) e na atualização de organizações (por exemplo, as de metrologia) visando ao controle da qualidade na indústria. Tais medidas, portanto, objetivavam também construir, reestruturar e fortalecer as organizações de apoio ao sistema de inovação no sentido de preparar a indústria local à competição internacional e também atrair novos fluxos de investimento estrangeiro produtivo.

No que se refere especificamente ao setor de TICs, em outubro de 1991 foi aprovada a Lei 8.248/91 que, por sua vez, substituía a antiga Lei 7.232, de 29/10/1984 (que regulamentava as restrições à entrada de capital estrangeiro e as importações de produtos). Também designada como "Lei de Informática", este novo marco regulatório do início dos anos 1990 objetivava o desenvolvimento do setor de TICs no Brasil sob novas condições econômicas e institucionais, mais especificamente, sob um novo regime de competição industrial (MCT, 2002). A nova Lei de Informática (regulamentada em 1993), passou a basear-se em um regime de incentivos fiscais voltados à implementação de atividades de P\&D em empresas desse setor Brasil. Este novo regime, por 
sua vez, tornou-se um dos mais importantes componentes institucionais do "sistema de inovação" no Brasil a partir do início dos anos 1990.

Com relação às reformas estruturais implementadas no início dos anos 1990, tem havido uma profusão de estudos sobre os efeitos dessa reestruturação econômica e institucional sobre indicadores de desempenho industrial, tais como produtividade do trabalho, produtividade total dos fatores e exportação (Cavalcanti \& Rossi, 2003). Alguns poucos estudos, no entanto, tem se preocupado com as implicações dessas mudanças para a inovação industrial. Por exemplo, Cimoli e Katz (2003), Katz (2004, 2005) e Sutz e Arocena (2004) argumentam que as reformas dos anos 1990 têm conduzido a um quadro no qual as atividades de $P \& D$ estariam cada vez mais concentradas em países industrializados, enquanto que as economias latino-americanas estariam se especializando na produção de commodities e na manufatura à base de simples montagem. Alinhando-se a essa perspectiva, outros estudos sugerem uma "trivialidade", ou mesmo inexistência, de vínculos baseados em atividades inovadoras entre empresas e demais componentes do "sistema de inovação" no Brasil (Viotti, 1997, 2000).

Em relação ao setor das TICs, mais especificamente, alguns estudos sugerem um desmantelamento das atividades tecnológicas inovadoras, especialmente, no campo das telecomunicações, como efeito à privatização e demais mudanças introduzidas no início dos anos 1990 (Szapiro \& Cassiolato, 2003; Mani, 2004). De maneira mais específica, Garcia e Roselino (2002) e Campos e Teixeira (2004), sugerem que a Lei de Informática implementada a partir do início dos anos 1990 não tem gerado os efeitos esperados em termos de geração de inovação, muito embora os próprios autores parecem reconhecer que seus estudos não examinaram o grau de capacidade tecnológica nas organizações beneficiárias da nova Lei de Informática.

Essa perspectiva pessimista sobre o setor de TIC no Brasil também é encontrada no Relatório Global de Tecnologia da Informação, elaborado no âmbito do Fórum Econômico Mundial, que avalia impacto das TICs no processo de desenvolvimento e competitividade das nações. Nas edições de 2004 e 2005 o Brasil aparece em $46^{\circ}$ e $52^{\circ}$ lugar, respectivamente, em termos de capacidade para alavancar as oportunidades criadas pelas TICs para incentivar e aumentar a competitividade desse setor (World Economic Forum/Insead, 
2005, 2006). ${ }^{3}$ Em sua edição de 2004-2005, afirma-se que "a América Latina sofre com poucas leis para o desenvolvimento do setor de tecnologia da informação; grandes obstáculos administrativos e burocráticos; falta de priorização do setor pelos governos; entre outros fatores negativos". Ocorre que um dos principais problemas desse tipo de estudo é a forte generalização de seus resultados e argumentos sem adequada fundamentação analítica, metodológica e de evidências empíricas.

Logo, a despeito das mudanças estruturais realizadas o Brasil desde o início da década de 1990, especialmente no setor das TICs, ainda há escassez de estudos sobre seus efeitos nas atividades tecnológicas inovadoras. Especificamente, muito embora tenham sido realizados vários esforços relativos à implementação da nova Lei de Informática, regulamentada em 1993, há uma escassez de estudos sistemáticos sobre grau de capacidade tecnológica, especialmente no contexto dos vários institutos de pesquisa em TICs que emergiram ou foram reestruturados a partir da nova Lei de Informática.

Por isso, este artigo objetiva identificar e mensurar tipos e níveis de capacidades tecnológicas em uma amostra de institutos de pesquisa em TICs no Brasil. Tais institutos caracterizam-se não apenas pelo fato de serem organizações de apoio ao sistema de inovação, mas, principalmente, pelo fato de serem organizações cujas atividades são fortemente baseadas em serviços intensivos em conhecimento técnico-científico. Considerando-se que a natureza das atividades desses institutos alinha-se às características das organizaçôes fortemente baseadas em serviços de intenso conteúdo técnico-científico, tal como definidas e estudadas em Castells (1989), Murphy e Vickrey (1999), Baark (2001), Gann e Salter (2003) e Miles (2003), os institutos examinados neste artigo são definidos como OSICs.

Portanto, neste artigo examina-se o grau de capacidade tecnológica em uma amostra de 18 dos principais institutos de pesquisa e desenvolvimento (P\&D) brasileiros, públicos e privados, orientados para o setor de TIC. Em paralelo, examinam-se duas fontes para a construção de capacidades tecnológicas: (i) os processos intra-organizacionais de aprendizagem e (ii) as

\footnotetext{
3 Trata-se de relatório de circulação internacional cuja audiência envolve líderes governamentais, empresariais e investidores. Porém, seus resultados precisam ser interpretados com cautela. Os aspectos analíticos e metodológicos relativos a este tipo de classificação, adotado também em relatórios similares gerados pelo Fórum Econômico Mundial, são duvidosos (ver crítica em Lall, 2001)
} 
ligações com empresas e outros componentes do sistema de inovação, como por exemplo, universidades, laboratórios, centros de treinamento e outros institutos de pesquisa.

A partir desta seção introdutória, a Seção 2 apresenta a base analítica do estudo, bem como suas métricas relacionadas. A Seção 3 descreve brevemente desenho e método do estudo subjacente a este artigo, enquanto que a Seção 4 examina as evidências empíricas do estudo. Finalmente, a Seção 5 encerra o artigo com as discussóes, conclusóes e recomendaçóes para estratégias corporativas e governamentais.

\section{Base analítica do estudo}

Esta seção apresenta a base conceitual por meio da qual as evidências empíricas deste estudo serão examinadas. Existem pelo menos duas perspectivas distintas que fornecem explicações para a maneira como países aceleram seu desenvolvimento industrial, principalmente no contexto de industrialização tardia: a teoria da acumulação e a teoria da assimilação.

Embora ambas as perspectivas reconheçam a importância de altos níveis de investimento em capital físico e capital humano, os seus mecanismos causais diferem. A perspectiva de acumulação enfatiza que a oferta de investimentos em capital físico e capital humano são suficientes, uma vez que empresas otimizarão tais recursos a partir de acesso simétrico à informação e ao conhecimento (Chenery et al., 1986).

Diferentemente, a perspectiva de assimilação (Dosi, 1988; Lall, 1990, 1992; Nelson, 1992; Bell \& Pavitt, 1993, 1995) enfatiza o papel da acumulação de conhecimento, via processos de aprendizagem (uma vez que firmas possuem acesso assimétrico à informação e ao conhecimento), para a implementação de estratégias de inovação voltadas para aceleração do crescimento econômico. Por isso, deveriam receber atenção governamental e da sociedade em proporção similar á atenção dada à acumulação de "fatores primários".

O estudo subjacente a este artigo alinha-se à "perspectiva da assimilação", pela sua robustez analítica e empírica para explicar processos de inovação em níveis de empresas, setores industriais, regiôes e países ao longo das últimas décadas. Um dos pontos centrais da aplicação dessa teoria, entretanto, é a perspectiva adotada para capacidade tecnológica e inovação. 


\subsection{Capacidade tecnológica em nível organizacional: definição e modelo de mensuração}

Essa capacidade envolve um conjunto de recursos (ou base de conhecimento), recursos estes que podem ser tangíveis (na forma de sistemas técnicofísicos, base de dados, software), codificados (produtos, patentes, procedimentos) ou intangíveis, tácitos, codificáveis, e não-codificáveis que estão incorporados em diversas dimensões da organização (técnicas de gestão e produção, rotinas organizacionais (implícitas e explícitas), estruturas organizacionais, valores e normas da organização (ver, por exemplo, Penrose, 1959; Nelson \& Winter, 1982; Bell \& Pavitt, 1993; Teece \& Pisano, 1994; Lall, 1992; Figueiredo, 2001 , 2004). Mais precisamente, tais recursos existem na forma de sistemas técnico-físicos (banco de dados, equipamentos, instalações físicas para o desenho e produção de bens e serviços), habilidades e qualificações das pessoas que constroem tais sistemas técnico-físicos, os produtos da organização (bens e serviços) e o sistema organizacional) - na forma de rotinas organizacionais, sistemas gerenciais, procedimentos, técnicas de gestão - que facilita (ou impede) a integração e coordenação entre as outras três dimensões da capacidade tecnológica (Figueiredo, 2001, 2004a).

Alinhando-se a Bell \& Pavitt (1993, 1995) e Figueiredo (2001), adota-se aqui uma distinção entre capacidade tecnológica para operar e usar tecnologias e sistemas de produção existentes (capacidades tecnológicas rotineiras) e capacidades para inovar tecnologias e sistemas técnico-organizacionais (capacidades tecnológicas inovadoras). Inovação, por sua vez, envolve um conjunto de atividades as quais variam de cópia, imitação, experimentação, adaptação até atividades mais sofisticadas de engenharia de desenvolvimento e design à base das várias modalidades de pesquisa. Essa perspectiva ampliada de inovação, que transcende a visão convencional confinada em atividades formais de $P \& D$, é particularmente importante para examinar grau de capacidade tecnológica inovadora no contexto de organizações que operam em países em desenvolvimento (Dosi, 1988; Lall, 1992; Bell \& Pavitt, 1993, 1995; Ariffin, 2000; Figueiredo, 2001; 2006). ${ }^{4}$

\footnotetext{
4 Para um argumento elaborado sobre essa perspectiva ampliada sobre inovação, principalmente para o contexto de organizações que operam no contexto de economias de industrialização tardia ver Lall (1990, 1992), Bell \& Pavitt (1993, 1995), Kim (1997); Dutrénit, 2000; Ariffin (2000); Figueiredo (2001, 2006).
} 
Mais especificamente, essa perspectiva compreensiva para capacidade tecnológica e inovação tem implicações para a maneira como examinamos essas questões em nível de organizações. Antes de se apresentar a métrica aqui adotada, é preciso clarificar por que não se adotam aqui os indicadores convencionais de medição de inovação. $\mathrm{O}$ primeiro deles refere-se aos indicadores à base de gastos e existência de laboratórios formais de P\&D, estatísticas de patentes, de artigos científicos publicados e de recursos humanos qualificados. As limitações desses indicadores para aferir o grau de capacidade tecnológica inovadora no contexto de economias de industrialização recente encontram-se bem elaboradas e documentadas na literatura (ver, por exemplo, Lall, 1990, 1992; Bell \& Pavitt, 1993, 1995; Ariffin \& Bell, 1999; Ariffin, 2000; Figueiredo, 2001, 2002; 2004; Ariffin \& Figueiredo, 2004).

Em segundo lugar, é importante mencionar que, no caso do setor de TIC, capacidade tecnológica é normalmente mensurada com base no Capability Maturity Model (CMM) do Software Engineering Institute (CMM-SEI), Carnegie Mellon University (CMU). O CMM é um modelo gerenciado pelo SEI para avaliação da maturidade de processamento de software de uma organização e identificação das práticas requeridas para o aumento de tal maturidade. No entanto, como argumentado em Baskerville e Pries-Heje (1999), Tschang et al. (2003), Marins (2005), e Miranda (2005), o CMM mostra-se cada vez mais limitado para mensurar capacidade tecnológica em organizações do setor de TIC. ${ }^{5}$

Por isso, optou-se por não se mensurar as capacidades tecnológicas dos institutos de P\&D unicamente e isoladamente com base nos pré-requisitos e especificações da certificação CMM. Não obstante, a construção da métrica específica (a ser apresentada na Seção 2.1.1), buscou, em vários aspectos, uma equivalência com alguns dos estágios do CMM.

\footnotetext{
O CMM baseia-se em uma perspectiva linear das atividades tecnológicas realizadas por uma organização da indústria de software. O CMM foi originalmente criado para certificar grandes empresas de software que objetivavam fornecer as forças armadas dos EUA. Seu foco, portanto, centra-se na capacidade da empresa em cumprir prazos e garantir a qualidade final do produto gerado. Isto, por sua vez, reflete pouca importância dada às outras atividades técnicoorganizacionais de uma organização de TIC. Uma vez que o CMM foi criado à base de um conjunto de boas práticas, visando grandes organizações, o custo de aplicá-las em organizações de médio e pequeno porte é, muitas vezes, proibitivo. Por isso, há organizações que alcançam níveis de inovação em atividades de TICs, mas que não possuem a certificação CMM. Ademais, o modelo CMM-SEl está exclusivamente centrado na atividade de desenvolvimento de software, a qual não é a única função tecnológica crucial para organizações orientadas para o setor de TIC. Para mais detalhes sobre as limitações do CMM como indicador de capacidade tecnológica organizações baseadas em TIC, especialmente no caso de software, ver Miranda (2005).
} 
TABELA 1

Métrica para avaliar capacidades tecnológicas em organizações de Tecnologia de Informação e Comunicação (TIC) em economias em desenvolvimento

\begin{tabular}{l|l|l|l}
\hline $\begin{array}{l}\text { Níveis de } \\
\text { capacidades } \\
\text { tecnológicas }\end{array}$ & Atividades de engenharia e gestão de projetos & $\begin{array}{l}\text { Produtos } \\
\text { e soluções }\end{array}$ & $\begin{array}{l}\text { Ferramentas } \\
\text { e processos }\end{array}$
\end{tabular}

\begin{tabular}{|c|c|c|c|c|}
\hline $\begin{array}{l}\text { Nível } 1 \\
\text { Básico }\end{array}$ & $\begin{array}{l}\text { Ferramentas básicas } \\
\text { e tecnologias } \\
\text { preexistentes de } \\
\text { desenvolvimento } \\
\text { de software. Práticas } \\
\text { de gestão incipientes. } \\
\text { Ambiente instável } \\
\text { para o desenvolvi- } \\
\text { mento de software e } \\
\text { atividades de P\&D } \\
\text { correlacionadas. }\end{array}$ & $\begin{array}{l}\text { Práticas internas de } \\
\text { gestão de projetos } \\
\text { informais e intermi- } \\
\text { tentes. Imprevisibi- } \\
\text { lidade de prazos, } \\
\text { orçamentos, funcio- } \\
\text { nalidade e qualidade } \\
\text { do produto. Gestão } \\
\text { de projetos realizada } \\
\text { pelos clientes. }\end{array}$ & $\begin{array}{l}\text { Replicação de } \\
\text { especificações } \\
\text { determinadas pelos } \\
\text { clientes. Pequenas } \\
\text { adaptações de } \\
\text { tecnologias já } \\
\text { existentes. }\end{array}$ & $\begin{array}{l}\text { Uso de ferramentas } \\
\text { básicas de enge- } \\
\text { nharia de software. } \\
\text { Processos operacio- } \\
\text { nais não forma- } \\
\text { lizados. Técnicas de } \\
\text { controle de } \\
\text { qualidade } \\
\text { incipientes. }\end{array}$ \\
\hline
\end{tabular}

CAPACIDADES TECNOLÓGICAS INOVADORAS

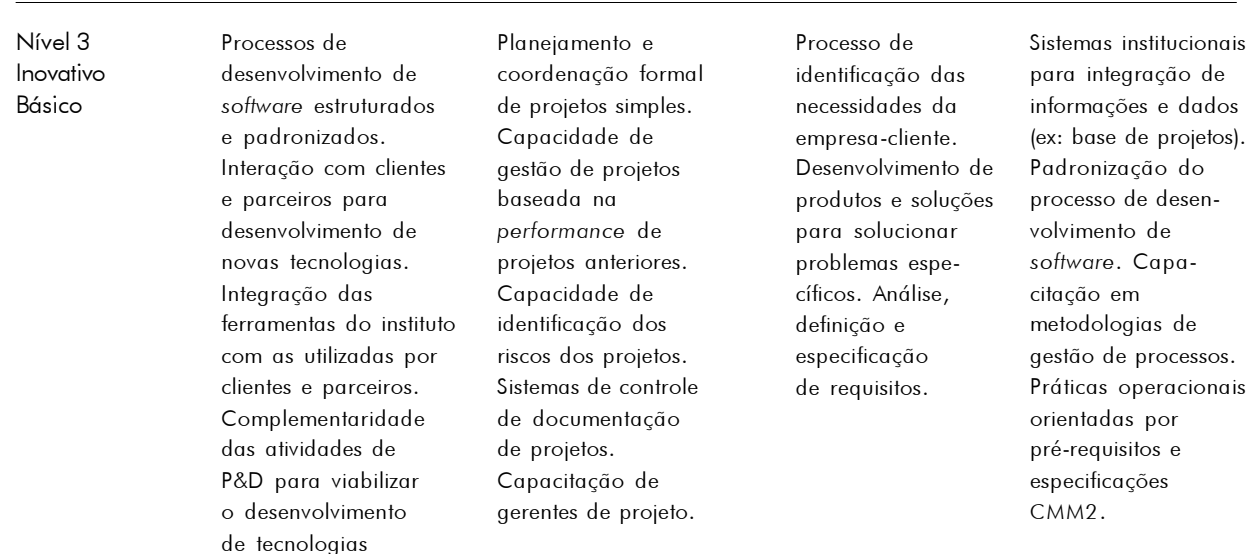


TABELA 1 (continuação)

Métrica para avaliar capacidades tecnológicas em organizações de Tecnologia de Informação e Comunicação (TIC) em economias em desenvolvimento

\begin{tabular}{l|l|l|l}
\hline $\begin{array}{l}\text { Níveis de } \\
\text { capacidades } \\
\text { tecnológicas }\end{array}$ & Atividades de engenharia e gestão de projetos & $\begin{array}{l}\text { Produtos } \\
\text { e soluções }\end{array}$ & $\begin{array}{l}\text { Ferramentas } \\
\text { e processos }\end{array}$
\end{tabular}

\begin{tabular}{|c|c|}
\hline & $\mathrm{CAP}$ \\
\hline $\begin{array}{l}\text { Nível } 4 \\
\text { Intermediário }\end{array}$ & $\begin{array}{l}\text { Integração das ferra- } \\
\text { mentas do instituto } \\
\text { com as utilizadas por } \\
\text { clientes e parceiros. } \\
\text { Complementaridade } \\
\text { das atividades de } \\
\text { P\&D para viabilizar } \\
\text { o desenvolvimento } \\
\text { de tecnologias } \\
\text { inovadoras. }\end{array}$ \\
\hline
\end{tabular}

Nível 5

Intermediáriosuperior

\section{Nível 6}

Avançado

\section{Equipes}

multidisciplinares, rotativas, de alta especialização tecnológica. Soluções inovadoras em engenharia de software e novas tecnologias a partir de insights próprios. Desenvolvimento de software em conjunto com centros globais.

Centro de P\&D de
excelência mundial
no desenvolvimento
de novas tecnologias
(ex: games, grid
computing,
messaging, iDEN).

Centro de P\&D de excelência mundia computing, messaging, iDEN).

\section{Gestão de projetos} de classe mundial. Gerência de equipes fisicamente distantes. Capacidade próativa de reconhecer fraquezas. Prevenção da ocorrência de falhas em processos e de defeitos em produtos.
Interação com o mercado global. Desenvolvimento de produtos e soluções em tecnologias de última geração (ex: TV digital, PDAs, integração, telefonia celular - CDMA, TDMA, GSM, iDEN).

Desenvolvimento de produtos e soluções de alta complexidade, com grande capacidade de personalização e adaptação para atender a necessidades ainda não identificadas via $P \& D$ (ex: grid computing, convergência, software zero defeito). Geração de spin-offs em decorrência da elevada especialização tecnológica.
Criação de novas unidades organizacionais. Fortalecimento das práticas de gestão de projetos. Gestão estratégica da qualidade; obtenção de certificações internacionais (ISO, PMP-PMI). Processos baseados em e controlados por web intranet. Práticas operacionais orientadas por pré-requisitos e especificações CMM3.

Transformação (reengenharia) dos processos críticos do instituto. Ferramentas avançadas de gestão de processos. Normas e padrões de projetos próprios (ex: Prosces). Execução de projetos envolvendo gestão de processos globais e simultâneos. Práticas operacionais orientadas por pré-requisitos e especificações CMM4.

Aprimoramento contínuo dos processos e sistemas operacionais, tanto a partir de avanços incrementais nos processos existentes quanto a partir de novos métodos e tecnologias. Práticas operacionais orientadas por pré-requisitos e especificações

Notas: iDEN: Integrated Digital Enhanced Network; PDAs: Personal Digital Assistants; CDMA: Code-Division Multiple Access; TDMA: Time Division Multiple Access; GSM: Global System for Móbile Communication; Prosces: Processo Padrão de Desenvolvimento de Software.

Fonte: Adaptado de Figueiredo (2001). Elaborado a partir de trabalho de campo e com base em métricas específicas existentes, tais como: Capability Maturity Model - Software Engineering Institute (CMM-SEI) e Project Management Body of Knowledge - Project Management Institute (PMBok - PMI)). 


\subsubsection{Métrica alternativa para capacidade tecnológica em nível organizacional}

A métrica utilizada para mensuração de capacidade tecnológica neste estudo baseia-se na taxionomia desenvolvida em Figueiredo (2001), adaptada de Lall (1992) e Bell e Pavitt (1995), na qual a capacidade tecnológica é medida a partir de atividades técnico-organizacionais que as organizações são capazes de realizar, de maneira independente (Tabela 1). A origem, princípios e detalhes conceituais sobre essa métrica, bem como sua aplicação empírica em outros setores industriais estão elaborados e documentados em Lall (1990, 1992); Bell e Pavitt (1995); Figueiredo (2001, 2002, 2003, 2004); Ariffin e Bell (1999); Ariffin e Figueiredo (2004) e Tacla e Figueiredo (2006).

A métrica aqui adotada (Tabela 1 ) torna-se útil para examinar a capacidade tecnológica de organizações de TIC em economias em desenvolvimento, uma vez que diferencia os tipos e niveis de capacidades para diversas funções tecnológicas. O modelo proporciona uma base para a descrição das capacidades tecnológicas desde um nível básico, onde estão presentes as atividades de rotina, até níveis de capacidades inovadoras, com diferentes graus de dificuldade para as funções tecnológicas. Além disso, a métrica envolve funções tecnológicas diversas.

Mais especificamente, as OSICs operam à base de intensa atividade criativa e inovadora e, por isso, são intensivas em conhecimento técnico-científico. Muito embora grande importância seja dada às OSICs como componentes-chave da economia de serviços e da economia baseada no conhecimento (Miles, 2003), há escasso conhecimento sobre a gestão do processo de construção e sustentação de capacidade tecnológica nesse tipo de organização, particularmente no contexto de uma economia em industrialização como é o caso do Brasil. É a partir do entendimento sobre a natureza da gestão de capacidade tecnológica nesse tipo de organização que estratégias corporativas e governamentais poderão ser desenhadas para acelerar o processo inovador nesse setor industrial. A geração de tal entendimento, entretanto, envolve um exame sistemático - ou mensuração - dos tipos e níveis de capacidade tecnológica desenvolvida nas organizaçôes do setor. Ou seja, pode-se gerenciar (e mudar) melhor aquilo que se pode medir. 


\subsection{Fontes para a construção e desenvolvimento de capacidade tecnológica}

No estudo subjacente a este artigo são identificadas suas fontes para as capacidades tecnológicas: os processos intra-organizacionais de aprendizagem e as ligações estabelecidas entre os institutos estudados e as demais organizações do sistema de inovação (incluindo as empresas).

\subsubsection{Processos intra-organizacionais de aprendizagem tecnológica}

Este tema envolve, por sua vez, duas abordagens: "aprendizagem organizacional" e a perspectiva da "base de conhecimento" da empresa (ver detalhes conceituais e empíricos elaborados em Figueiredo, 2001, 2003). A avaliação dos processos de aprendizagem, como fontes de capacidade tecnológica nos institutos da amostra, é feita à luz da taxionomia desenvolvida em Figueiredo $(2001,2003)$ e indicado na Tabela 2.

O modelo identifica quatro processos de aprendizagem (processos de aquisição interna e externa de conhecimento e os processos de compartilhamento e de codificação de conhecimento). Neste estudo, examina-se somente a "variedade" ou incidência dos processos de aprendizagem. ${ }^{6}$

\subsubsection{Ligações estabelecidas entre os institutos e demais componentes do sistema de inovação}

Além da perspectiva compreensiva sobre inovação (apresentada acima), adota-se aqui uma visão sistêmica do processo de inovação (ver, por exemplo, Freeman, 1982; 1994; Kline \& Rosenberg, 1986; Mowery \& Nelson, 2003; Fagerberg et al., 2005). Rejeita-se, principalmente, a idéia de que inovação simplesmente flui de algum processo anterior de descoberta ou invenção

\footnotetext{
O modelo original identifica quatro características-chave dos processos intra-organizacionais de aprendizagem (variedade, intensidade, funcionamento e interação, ver Figueiredo, 2001). Porém, em função das limitações operacionais de coleta de evidências empíricas, com adequado grau de detalhe e profundidade durante os trabalhos de campo deste estudo, optou-se, já durante a etapa de desenho do estudo, por não examinar as outras três características. Isto, por sua vez, significa uma das limitações do foco de análise deste estudo.
} 
TABELA 2

Modelo para examinar os processos intra-organizacionais aprendizagem tecnológica

Tipos de processos de aprendizagem

Processos de aquisição de conhecimentos externos

Processos de aquisição de conhecimentos internos

Processos de compartilhamento de conhecimentos (de nível individual para níveis de grupo e organzacional)

Processos de codificação de conhecimentos

\section{Definição}

São os processos pelos quais os indivíduos adquirem conhecimentos tácitos e/ou codificados vindos de fora da empresa. Para tanto, pode-se importar saber externo, recorrer à assistência técnica e promover treinamento no exterior. Outros meios seriam a canalização sistemática de saber externo codificado, o convite a especialistas para dar conferências, etc.

São os processos pelos quais os indivíduos adquirem conhecimentos tácitos exercendo diferentes atividades na empresapor exemplo, cumprindo tarefas rotineiras ou aperfeiçoando os processos e a organização da produção, os equipamentos e os produtos existentes. Isso também pode ser feito em centros de P\&D formalmente organizados, nos laboratórios da empresa e/ou mediante experimentação sistemática nas diversas unidades operacionais.

São os processos pelos quais os indivíduos compartilham seu saber tácito (modelos mentais e aptidões técnicas). Em outras palavras, todo processo, formal ou informal, pelo qual o saber tácito é transmitido de um indivíduo ou grupo de indivíduos para outro, o que pode envolver observação, reuniões, solução conjunta de problemas e rotatividade de tarefas. $O$ treinamento também pode ser um processo de socialização de conhecimentos. Por exemplo, durante os programas de treinamento, indivíduos com diferente formação e experiência podem socializar seu saber tácito com estagiários e instrutores. Nosso modelo leva em conta diferentes tipos de treinamento, como treinamento interno (cursos), treinamento no emprego (OJT) e treinamento para empregados de outras empresas. Esses tipos de treinamento podem ser precedidos de treinamento básico (aritmética e linguagem).

São os processos pelos quais o saber tácito individual (ou parte dele) se torna explícito. Em outras palavras, os processos pelos quais o saber tácito é expresso em conceitos explícitos, de forma organizada e acessível, tornando-se mais facilmente assimilável. Portanto, o processo facilita a disseminação dos conhecimentos na empresa, podendo envolver padronização dos métodos de produção, documentação e seminários internos. A organização de módulos de treinamento pelo pessoal interno pode envolver processos tanto de socialização quanto de codificação do saber. Logo, os processos 3 e 4 são cruciais para a conversão da aprendizagem individual em aprendizagem organizacional.

\section{Nuances de \\ sua incidência}

Ausente -

Presente [Limitada -

Moderada-Diversa]

Fonte: adaptado de Figueiredo $(2001,2003)$. 
científica ou tecnológica. A adoção dessa perspectiva sistêmica justifica-se de duas maneiras. Primeira, inovação não é um processo linear (ou seja, que envolve um fluxo pesquisa, desenvolvimento à produção), mas um processo que envolve uma variedade de atividades criativas inter-relacionadas e complementares em nível organizacional. Segunda, inovação é vista como um processo de interação entre empresas e demais organizações do sistema de inovação.

Por isso, a segunda fonte para construção de capacidade tecnológica examinada aqui se refere às ligaçôes estabelecidas entre os institutos da amostra e os demais componentes do sistema nacional de inovação. Tais componentes envolvem, por exemplo, empresas de TIC, empresas de consultoria, departamentos de universidades, laboratórios públicos e privados, centros de metrologia, outros institutos de pesquisa públicos e privados centros de treinamento, entre outras. Para o exame de tais ligaçôes utiliza-se aqui uma adaptação do modelo desenvolvido em Vedovello (1995). ${ }^{7}$ Este modelo divide as ligações em três grupos, de acordo com sua natureza, a saber: ligações informais, de recursos humanos e formais.

As ligações informais não são estabelecidas por contrato e, a princípio, não envolvem pagamentos financeiros. As ligações de recursos humanos estão voltadas para treinamento e capacitação profissional. Por fim, as ligações formais pressupõem o estabelecimento de contratos formais, com comprometimento de ambas as partes e realização de pagamentos acordados previamente. Além de examinar as ligaçóes de acordo com sua natureza (Tabela 3), o modelo adaptado de Vedovello (1995) permite o exame da freqüência, resultados e benefícios gerados para os parceiros envolvidos nas ligações (Tabela 4).

\section{Desenho e método do estudo}

Este estudo foi desenhado para examinar tipos e níveis de capacidade tecnológica, bem como as principais fontes para essas capacidades em uma amostra de 18 dos mais importantes institutos de pesquisa relacionados ao setor de TIC no Brasil. O critério-chave utilizado para composição da amostra

\footnotetext{
7 Muito embora o modelo tenha originalmente sido concebido para examinar a relação entre universidades e empresas (Vedovello, 1995), este modelo tem sido adaptado no sentido de torná-lo apto a examinar fontes a natureza das ligações estabelecidas entre várias organizações do sistema de inovação. Ver recentes adaptações e aplicações de desse modelo, em sua versão ampliada, em Figueiredo et al. (2005) e Vedovello \& Figueiredo (2006).
} 
TABELA 3

Modelo para examinar a natureza das ligações entre organizações de apoio ao sistema de inovação

Tipos de Definição
ligação

Ligações As ligações que integram este grupo são aquelas que informais representam um contato inicial entre empresas e organizações de apoio ao sistema de inovação. Assim, através deste grupo de ligações, as empresas, em suas buscas por soluções técnicas ou em suas tentativas de implementar uma inovação, estabelecem contatos com informações e conhecimento, expertise e equipamentos disponíveis nas organizações de apoio (universidades, institutos de pesquisa, centros de formação). Por outro lado, essas organizações estabelecem contatos com as empresas e suas competências e necessidades tecnológicas. O estabelecimento destas ligações não implica o estabelecimento de contratos formais entre os parceiros, muito embora pequenas taxas possam estar, algumas vezes, envolvidas em uma base ad hoc.

Recursos As ligações à base de formação de recursos humanos estão humanos relacionadas com a melhoria, treinamento e recrutamento e/ou alocação de recursos humanos qualificados. Empresas, por exemplo, podem desejar fortalecer suas ligações com organizações de apoio ao sistema de inovação através do suporte a, ou absorção de, recursos humanos mais qualificados. Este grupo de ligações também amplia as possibilidades de promoção de educação continuada e técnica em áreas de interesse específico das empresas. Do ponto de vista das organizações de apoio, pesquisadores individuais ou mesmo uma unidade (de pesquisa) específica, podem desejar fortalecer suas ligações com empresas objetivando aumentar a oferta de posições de trabalho para os seus recursos humanos mais qualificados e ampliar a base educacional ou o seu porffolio de pesquisa.

Ligações Através deste grupo de ligações, e conscientes dos recursos formais disponíveis nas organizações de apoio ao sistema de inovação (universidades, institutos de pesquisa, etc.) - conhecimento e informação, recursos humanos qualificados, e equipamentos as empresas podem desejar contratar a utilização de um equipamento específico ou contratar projetos de pesquisa, em bases individuais ou coletivas, ou desenvolver projetos de pesquisa conjunto para apoiar e complementar seus esforços tecnológicos internos. Do ponto de vista das organizações de apoio, após estabelecer familiaridade com o ambiente empresarial e suas competências científicas e tecnológicas, podem desejar fazer uso de equipamentos industriais ou oferecer sua expertise científica para as empresas, ampliando, conseqüentemente, seus portfolios de pesquisa e seus rendimentos financeiros, através do desenvolvimento de contratos de pesquisa ou o desenvolvimento de pesquisa conjunto. Geralmente, estas ligações pressupõem o estabelecimento de contratos formais entre os parceiros, onde o compromisso e o pagamento de taxas são previamente estabelecidos.

\author{
Mecanismos para sua \\ operacionalização
}

1. Contatos informais com pesquisadores/empresários 2. Acesso à literatura especializada 3. Acessos à pesquisa de departamentos específicos 4. Participação em seminários e conferências

5. Acessos a equipamentos da universidade e/ou dos institutos de pesquisa e/ou das empresas 6. Participação em programas específicos (educacionais e de treinamento)

7. Outras ligações informais

1. Envolvimento de estudantes em projetos

2. Recrutamento de recémgraduados

3. Recrutamento de cientistas e engenheiros mais experientes 4. Programas de treinamento formalmente organizados para atender às necessidades dos recursos humanos

5. Ouras ligações de recursos humanos

1. Consultoria desenvolvida por pesquisadores ou consultores 2. Análises e testes (ensaios técnicos)

3. Serviços de atualização de acervo (normas técnicas utilizadas, patentes)

4. Respostas técnicas (diagnóstico de problemas em termos de processo produtivo)

5. Estabelecimento de contratos de pesquisa (como desenvolvimento de software)

6. Estabelecimento de pesquisa conjunta

7. Outras ligações formais

Fonte: adaptado de Vedovello (1995), Figueiredo et al., (2005), e Vedovello \& Figueiredo (2006). 
TABELA 4

Níveis de classificação das ligações com demais organizações de apoio ao sistema de inovação

\begin{tabular}{ll}
\hline Em termos de freqüência & F1 $=$ até 2 vezes ao ano \\
& F2 $=$ de 3 a 6 vezes ao ano \\
& F3 $=$ uma vez por mês \\
& F4 $=$ uma vez por semana ou mais \\
Em termos de resultados obtidos $\quad$ R1 $=$ conselhos verbais \\
R2 $=$ fornecimento de informações \\
R3 $=$ relatórios \\
R4 $=$ implementação de programas específicos \\
R5 $=$ especificações de design \\
R6 $=$ protótipos \\
R7 $=$ patentes \\
R8 $=$ outros \\
Bm termos de benefícios alcançados nenhum \\
B2 = pequeno benefício \\
B3 = benefício moderado (complementar) \\
B4 = grande benefício (crucial)
\end{tabular}

Fonte: adaptado de Vedovello (1995), Figueiredo et al., (2005), e Vedovello \& Figueiredo (2006).

foi o de amostra intencional no sentido de compor uma amostra com os mais importantes institutos no Brasil. Tal estratégia, por sua vez, permite a seleção de casos representativos que podem ser fonte de informações centrais para os propósitos da pesquisa (Patton, 1990; Figueiredo, 2004b). A identificação dos institutos estudados iniciou a partir de consulta a uma base de 172 organizações de ensino e pesquisa credenciadas pelo Comitê da Área de Tecnologia de Informação do Ministério da Ciência e Tecnologia (CATI/MCT) e a uma base de dados da Associação Brasileira da Indústria Elétrica e Eletrônica (ABNINEE).

Em paralelo, foram consultados três especialistas da indústria de TIC no Brasil, em diferentes organizaçôes localizadas em diferentes estados, no intuito de obter informaçôes sobre a relevância da amostra obtida a partir das fontes acima. Buscou-se uma amostra não apenas relevante, mas heterogênea em termos de localização geográfica, idade e natureza dos institutos. A amostra final 
resultou em 18 institutos distribuídos nas cinco grandes regiōes geográficas do Brasil. ${ }^{8}$ A amostra envolve institutos criados em momentos distintos: da década de 1960 aos criados em 2001. Por fim, com relação à natureza dos institutos, a amostra contém institutos de pesquisa públicos e privados, tanto ligados a universidades quanto independentes ou ligados a empresas. ${ }^{9}$

Contudo, uma característica comum aos institutos da amostra é que todos são beneficiários da Lei de Informática. ${ }^{10}$ Os incentivos concedidos (redução de taxas incidentes sobre a produção industrial e subseqüente redução gradual de seu valor) requerem, em contra partida, a aplicação de $5 \%$ da receita bruta das empresas beneficiadas em atividades de P\&D. As atividades de P\&D, por sua vez, devem ser tanto desenvolvidas internamente, pela própria empresa, quanto contratadas de universidades e institutos de P\&D locais (nacionais). Além disso, $0,5 \%$ desses recursos devem ser direcionados para o Fundo Setorial específico para Informática, o CT-INFO.

Os incentivos fiscais relativos à Lei de Informática foram estendidos até 2009 (Lei 10.176/01). Em 2004 a vigência deste arranjo fiscal foi prorrogada até 2019 (Lei 11.077/04), porém tal prorrogação apenas foi regulamentada em setembro de 2006 (ver Decreto 5.906, 26/9/2006). ${ }^{11}$

$\mathrm{O}$ estudo subjacente a este artigo baseia-se fortemente em evidências empíricas de primeira mão (primárias), qualitativas e quantitativas, colhidas diretamente dos institutos da amostra por meio de extensivo trabalho de campo que durou cerca de um ano em duas etapas: piloto e final. ${ }^{12}$ Especificamente, as fontes para a obtenção das evidências empíricas foram os diretores, gerentes, engenheiros e técnicos dos diversos institutos de pesquisa estudados, bem como dirigentes de outras organizaçôes com os quais estes se relacionam (empresas, universidades, centros de formação e treinamento, laboratórios), assim como documentos publicados pelos institutos e seus principais parceiros.

8 Optou-se por não apresentar aqui a lista dos institutos pesquisados.

9 Os critérios de localização geográfica, idade e natureza dos institutos foram utilizados aqui apenas no intuito de compor uma amostra heterogênea. Uma das limitações deste estudo é o fato de essas características não terem sido usadas como insumo empírico para explicar diferenças entre os institutos em termos de tipos e níveis de capacidade tecnológica e suas principais fontes.

10 A lei em vigência alinha-se à Política Industrial, Tecnológica e de Comércio Exterior (PITCE) do Governo Federal. Objetiva estimular a pesquisa e desenvolvimento e a inovação tecnológica no país por meio um regime fiscal específico.

11 Informações detalhadas sobre o regime fiscal subjacente a este lei, bem como uma ampla base de informações sobre as várias organizações beneficiárias encontra-se disponível em: www.mct.gov.br.

12 O estudo completo foi implementado durante o período de fevereiro de 2004 a maio de 2005. 
As evidências das fontes acima foram coletadas a partir de técnicas variadas: entrevistas, observação direta, encontros fortuitos e consulta a bases de dados. O exame das evidências empíricas consistiu na construção sistemática de tabelas analíticas, conforme os procedimentos sugeridos em Miles e Huberman (1984) e Figueiredo (2004b), e à luz dos modelos conceituais e métricas apresentadas na Seção 2.

Uma vez que os institutos da amostra foram criados em períodos de tempo distintos, e inspirando-se em Figueiredo (2001), foi elaborada uma estrutura simples de três fases comuns no intuito de facilitar a comparação entre as organizações estudadas, no que se refere aos processos intra-organizacionais de aprendizagem: (i) fase inicial (período em que os institutos iniciaram suas atividades), (ii) fase intermediária (período de transição que abrange principalmente o período do início dos anos 1990 a 2000, período este marcado pela abertura da economia brasileira à competição internacional, desregulamentação e privatização do setor de telecomunicações no Brasil, pela criação e implementação da Lei de Informática) e (iii) fase atual (relativa ao período do trabalho de campo). ${ }^{13}$

\section{Principais resultados do estudo}

\subsection{Tipos e níveis de capacidades tecnológicas dos institutos da amostra}

As evidências na Tabela 5 indicam os tipos e níveis de capacidades tecnológicas encontradas nos institutos da amostra durante o período em que o trabalho de campo foi realizado. Todos os institutos da amostra desenvolveram capacidades tecnológicas até o Nível 3 nas quatro funções examinadas.

\footnotetext{
13 No intuito de captarmos parte do dinamismo (ou mudança ao longo do tempo) da acumulação tecnológica nos institutos da amostra, foi possível um aprofundamento da coleta de evidências sobre a evolução dos processos intraorganizacionais de aprendizagem usados pelos institutos da amostra durante essas três fases. Porém, seria desejável se pudessem ter sido obtidas evidências sobre a acumulação, ao longo do tempo, dos tipos e níveis de capacidades tecnológicas, bem como da evolução das ligações entre os institutos e as demais organizações do sistema de inovação. Isto possibilitaria o entendimento do real dinamismo dessas variáveis ao longo do tempo. Ocorre que a implementação da fase piloto do estudo revelou que, no contexto específico deste projeto de pesquisa, a obtenção dessas evidências, com adequado grau de detalhe e profundidade sobre esses dois últimos temas, não seria possível. Por isso, uma das limitações deste estudo é o fato de não se realizar um exame, ao longo do tempo, das de todos os temas aqui examinados. Ou seja, uma parte deste estudo é estática.
} 
Nenhum instituto da amostra está confinado a níveis de capacidades de rotina. Em termos de capacidade para realizar atividades de engenharia de software a maioria dos institutos da amostra alcançou Níveis 5 e 6 (intermediário-superior e avançado, respectivamente). Embora apenas um instituto (5,5\%) tenha alcançado o Nível 6 de capacidade tecnológica, as capacidades do Nível 5 representam o nível máximo de capacidade em $11(61,1 \%)$ institutos nesta função. O Nível 4 (intermediário), por sua vez, representa o nível máximo de capacidade tecnológica para seis $(33,3 \%)$ dos institutos pesquisados. As evidências apontam que o instituto que consolidou as capacidades do Nível 6 nesta função tornou-se recentemente um centro de referência não apenas no Brasil, mas também internacionalmente, em desenvolvimento de software.

Em termos de gestão de projetos, $12(66,6 \%)$ institutos da amostra alcançaram o Nível 4 (intermediário) como maior nível de capacidade para realizar este tipo de função tecnológica. O Nível 3 (inovação básica), representa o nível máximo alcançado por quatro $(22, \%)$ institutos. Por fim, o Nível 5 (intermediário-superior), representa o nível máximo de capacitação em gestão de projetos de dois $(11,1 \%)$ institutos estudados: um independente e outro ligado a uma empresa de TIC. As evidências indicam que nesses institutos a gestão de risco é inerente à gestão de projetos. Adicionalmente, há a avaliação de performance por meio de métricas quantitativas. Apesar de, até o momento da realização da pesquisa de campo, nenhum instituto estudado ter consolidado as capacidades do Nível 6 (Avançado) na função gestão de projetos, as evidências empíricas sugerem que um instituto que se encontra no Nível 5 está construindo as capacidades relativas ao Nível 6 nesta função.

Com relação à função produtos e soluções, apenas um $(5,5 \%)$ instituto permanece no Nível 3 (inovação básica). Dezessete institutos $(94,4 \%)$ alcançaram o Nível 4 (intermediário) nesta função enquanto que sete $(38,8 \%)$ moveram-se para o Nível 5 (intermediário-superior). Destes, apenas um moveu-se para o Nível 6 (avançado). As evidências apontam que o instituto que alcançou o Nível 6 de capacidade para realizar atividades relativas a produtos e soluçôes é capaz de desenvolver serviços de elevada complexidade, dotados de capacidade de personalização para atender necessidades ainda não identificadas. Além disso, há a geração de spin-offs por conta da complexidade e da especialização das atividades realizadas por este instituto. 
TABELA 5

Tipos e níveis de capacidades tecnológicas encontrados nos institutos da amostra durante o trabalho de campo

\section{Níveis de}

competência
Atividades de engenharia e gestão de projetos

Engenharia de software Gestão de projetos
Produtos

e soluções

Ferramentas e processos

CAPACIDADES TECNOLÓGICAS DE ROTINA

\section{Nível 1}

(Operações básicas)

18

$(100,0 \%)$

18

(Extrabásico)
18

$(100,0 \%)$

18

$(100,0 \%)$
18

$(100,0 \%)$

18

$(100,0 \%)$
18

$(100,0 \%)$

$(100,0 \%)$

CAPACIDADES TECNOLÓGICAS INOVADORAS

\begin{tabular}{|c|c|c|c|c|}
\hline $\begin{array}{l}\text { Nível } 3 \\
\text { (Inovação básica) }\end{array}$ & $\begin{array}{c}18 \\
(100,0 \%)\end{array}$ & $\begin{array}{c}18 \\
(100,0 \%)\end{array}$ & $\begin{array}{c}18 \\
(100,0 \%)\end{array}$ & $\begin{array}{c}18 \\
(100,0 \%)\end{array}$ \\
\hline $\begin{array}{l}\text { Nível } 4 \\
\text { (Inovação } \\
\text { intermediária) }\end{array}$ & $\begin{array}{c}18 \\
(100,0 \%)\end{array}$ & $\begin{array}{c}14 \\
(77,7 \%)\end{array}$ & $\begin{array}{c}17 \\
(94,4 \%)\end{array}$ & $\begin{array}{c}8 \\
(44,4 \%)\end{array}$ \\
\hline $\begin{array}{l}\text { Nível } 5 \\
\text { (Inovação } \\
\text { intermediária superior) }\end{array}$ & $\begin{array}{c}12 \\
(66,6 \%)\end{array}$ & $\begin{array}{c}2 \\
(11,1 \%)\end{array}$ & $\begin{array}{c}7 \\
(38,8 \%)\end{array}$ & $\begin{array}{c}1 \\
(5,5 \%)\end{array}$ \\
\hline $\begin{array}{l}\text { Nível } 6 \\
\text { (Inovação avançada) }\end{array}$ & $\begin{array}{c}1 \\
(5,5 \%)\end{array}$ & $\begin{array}{c}0 \\
(0,0 \%)\end{array}$ & $\begin{array}{c}1 \\
(5,5 \%)\end{array}$ & $\begin{array}{c}0 \\
(0,0 \%)\end{array}$ \\
\hline
\end{tabular}

Fonte: derivado da pesquisa de campo.

Finalmente, em relação à função de ferramentas e processos todos os institutos estudados são capazes de realizar atividades relativas ao Nível 3 de capacidade tecnológica. Porém, apenas oito moveram-se para o Nível 4 (intermediário). Destes, apenas um instituto avançou até o Nível 5 (intermediáriosuperior). Trata-se de um instituto independente. 


\subsection{Processos intra-organizacionais de aprendizagem nos institutos da amostra}

As Tabelas 6 e 7 indicam que a variedade dos processos de aprendizagem intra-organizacionais utilizados pelos institutos estudados durante sua fase atual apresenta crescimento considerável em relação à fase intermediária e, em especial, à fase inicial. No que se refere aos processos de aquisição externa de conhecimento, na fase inicial, o processo mais utilizado pelos institutos estudados era a realização de treinamentos conforme a identificação das necessidades dos institutos, presente em 14 (77,7\%) casos. Entretanto, na fase inicial, os treinamentos externos não seguiam uma programação pró-ativa, sendo realizados quando se identificava uma demanda ou deficiência do instituto. Ainda na fase atual, a interação para desenvolvimento de projetos acontecia com maior freqüência com parceiros nacionais, estando presente em 13 (72,2\%) institutos.

$\mathrm{Na}$ fase intermediária, os processos de aquisição externa de conhecimento mais freqüentes eram a realização de treinamentos conforme levantamento de necessidades, a participação em congressos e seminários e a interação com parceiros nacionais. Durante a fase atual, os três mecanismos predominantes na fase intermediária foram encontrados nos 18 (100,0\%) institutos estudados - como, por exemplo, a consulta à legislação, normas e regulamentação, a interação com clientes nacionais e a participação em palestras e cursos relacionados às TICs. Em termos de aquisição interna de conhecimento, inicialmente, os três processos mais utilizados pelos institutos estudados estão presentes em $13(72,2 \%)$ institutos, sendo dois referentes às atividades internas de $\mathrm{P} \& \mathrm{D}$ - design e desenvolvimento exploratório e aplicações de engenharia.

Durante a fase intermediária, a atividade de design ainda era o mecanismo mais utilizado pelos institutos estudados. $\mathrm{O}$ mecanismo de aquisição externa e interna de conhecimento que apresentava maior crescimento (em termos de número de institutos que o utilizam) era a aprendizagem por busca. Na fase atual, os processos de aquisição interna de conhecimento mais presentes são os mesmos da fase inicial, estando a atividade de desenvolvimento exploratório e aplicações de engenharia presente em todos os institutos da amostra. Destacase também a pesquisa aplicada, hoje presente em 16 (88,8\%) institutos.

Com relação aos processos de compartilhamento de conhecimento, 


\section{TABELA 6}

\section{Incidência dos processos de aquisição de conhecimento nos institutos da amostra}

[Número à esquerda representa a soma dos institutos nos quais o mecanismo de aprendizagem está presente. Número entre parênteses representa percentual em relação ao total de institutos da amostra]

Processos e mecanismos de aquisição externa de conhecimento

1. Contratação de especialistas para desenvolvimento de capacitação em assistência técnica e engenharia

2. Contratação de consultores externos para certificações e desenvolvimento de sistemas operacionais/gerenciais

3. Treinamento externo em microinformática

4. Treinamento externo de longa duração no exterior

5. Outros treinamentos conforme levantamento de necessidades

6. Palestras e cursos relacionados a desenvolvimento de software e TIC

7. Programa de desenvolvimento de gerentes de projeto

8. Realização de cursos de idiomas a partir de incentivos do instituto

9. Realização de cursos de graduação a partir de incentivos do instituto

10. Realização de cursos de pós-graduação a partir de incentivos do instituto

11. Participação em congressos e seminários

12. Publicação e apresentação de artigos

13. Seminários de tecnologia com clientes (nacionais)

14. Seminários de tecnologia com clientes (internacionais)

15. Seminários de tecnologia com parceiros (nacionais)

16. Seminários de tecnologia com parceiros (internacionais)

17. Interação para desenvolvimento de projetos com clientes (nacionais)

18. Interação para desenvolvimento de projetos com clientes (internacionais)

19. Interação para desenvolvimento de projetos com parceiros (nacionais)

20. Interação para desenvolvimento de projetos com parceiros (internacionais)

21 . Aquisição de tecnologia desenvolvida por outras unidades (do instituto/da empresa/da universidade)

22. Aquisição de tecnologia desenvolvida por terceiros

23. Consulta a patentes

24. Legislação, normas, regulamentação

$\begin{array}{lcc}\text { Fase } & \text { Fase } & \text { Fase } \\ \text { Inicial } & \text { Intermediária } & \text { Atual }\end{array}$

$\begin{array}{rrr}10(55,5) & 14(77,7) & 15(83,3) \\ 9(50,0) & 9(50,0) & 15(83,3) \\ 8(44,4) & 11(61,1) & 14(77,7) \\ 8(44,4) & 9(50,0) & 12(66,6) \\ 14(77,7) & 15(83,3) & 18(100,0) \\ 12(66,6) & 14(77,4) & 18(100,0) \\ 4(22,2) & 8(44,4) & 14(77,7) \\ 6(33,3) & 8(44,4) & 11(61,1) \\ 5(27,7) & 9(50,0) & 12(66,6) \\ 8(44,4) & 11(61,1) & 16(88,8) \\ 13(72,2) & 15(83,3) & 18(100,0) \\ 9(50,0) & 12(66,6) & 16(88,8) \\ 9(50,0) & 12(76,6) & 15(83,3) \\ 4(22,2) & 8(44,4) & 14(77,7) \\ 9(50,0) & 13(72,2) & 16(88,8) \\ 8(44,4) & 9(50,0) & 13(72,2) \\ 11(61,1) & 14(87,4) & 18(100,0) \\ 6(33,3) & 11(61,1) & 15(83,3) \\ 13(72,2) & 15(83,3) & 18(100,0) \\ 9(50,0) & 12(66,6) & 15(83,3) \\ 5(27,7) & 7(38,8) & 12(66,6) \\ 8(50,0) & 11(61,1) & 17(94,4) \\ 8(44,4) & 9(50,0) & 14(77,7) \\ 12(66,6) & 14(77,7) & 18(100,0) \\ & & \end{array}$

\section{Processos e mecanismos de aquisição interna de conhecimento}

25. Pesquisa básica

26. Pesquisa aplicada

27. Design

28. Desenvolvimento exploratório e aplicações de engenharia

29. Treinamento interno liderado por especialistas estrangeiros

30. Treinamento interno em desenvolvimento de software

31. Treinamento interno em software de projeto e processo

32. Participação de engenheiros recém-formados em projetos

33. Contratação e desenvolvimento de engenheiros trainees

34. Participação de especialistas do instituto em projetos no exterior

35. Desenvolvimento em engenharia de processos e projetos por meio de experimentação, comparação de dados interlaboratoriais

$\begin{array}{rrr}3(16,6) & 4(22,2) & 6(33,3) \\ 10(55,5) & 12(66,6) & 16(88,8) \\ 13(72,2) & 14(77,7) & 16(88,8) \\ 13(72,2) & 13(72,2) & 18(100,0) \\ 10(55,5) & 11(61,1) & 14(77,7) \\ 12(66,6) & 12(66,6) & 15(83,3) \\ 8(44,4) & 9(50,0) & 14(77,7) \\ 13(72,2) & 13(72,2) & 17(94,4) \\ 11(61,1) & 11(61,1) & 14(77,7) \\ 6(33,3) & 9(50,0) & 13(72,2) \\ 7(38,8) & 11(61,1) & 15(83,3)\end{array}$

Fonte: adaptado de Vedovello (1995), Figueiredo et al. (2005) e Vedovello \& Figueiredo (2006). 
durante a fase inicial, a realização de encontros de projetos nos institutos era o mecanismo de compartilhamento de conhecimento mais utilizado, conforme mostrado na Tabela 7. Destacam-se, ainda, os meios de comunicação convencional e a realização de intercâmbios com clientes e parceiros nacionais para a realização de projetos. $\mathrm{Na}$ fase intermediária, as modalidades de comunicação dinâmica passaram a ser utilizadas por $17(94,4 \%)$ institutos. O intercâmbio com clientes e parceiros nacionais passa a estar presente em 15 (83,3\%) institutos. Durante essa fase aumentou o número de institutos que realizavam esses intercâmbios com agentes internacionais. $\mathrm{Na}$ fase atual, os intercâmbios com clientes e parceiros nacionais e internacionais estão presentes, respectivamente, em $17(94,4 \%)$ e 15 (83,3\%) institutos. Já o mecanismo comitês de qualidade é encontrado em $12(66,6 \%)$ institutos, enquanto na fase inicial estava presente em apenas oito $(44,4 \%)$ dos institutos. Esse tipo de processo de aprendizagem pode jogar um papel crucial na renovação (ou descontinuidade) de certo tipo de capacidade tecnológica (ou base de conhecimento) existente na organização. Por exemplo, um dirigente de um dos institutos mais inovadores da amostra, comentou que encoraja a formação de grupos informais e temporários de trabalho para "criticar" e "desestruturar" processos e rotinas organizacionais existentes na busca por contínua renovação. Esta iniciativa reflete um esforço da gestão em evitar que a capacidade inovadora transforme-se em "capacidade limitante" por meio do "enrijecimento" das práticas inovadoras e da acomodação pelo sucesso da inovação (Leonard-Barton, 1995). Ademais, é a descontinuidade proposital dos processos de aprendizagem que permite que a organização se mova para níveis mais sofisticados de capacidade inovadora (Figueiredo, 2001, 2003).

Os processos de codificação de conhecimento representam o tipo de processo de menor incidência nos institutos estudados, em todas as três fases examinadas.

Enquanto a elaboração de normas e regulamentos internos é o mecanismo de codificação de conhecimento mais incidente nos institutos examinados em todas as fases, as certificações ISO e CMM são os mecanismos de menor incidência. Inicialmente presente em quatro $(22,2 \%)$ institutos, a certificação ISO foi encontrada em cinco $(27,7 \%)$ institutos, na fase intermediária, e em dez $(55,5 \%)$ institutos durante a fase atual. Por fim, a certificação CMM ainda não 
TABELA 7

Incidência dos processos de conversão de conhecimento nos institutos da amostra

[Número à esquerda representa a soma dos institutos nos quais o mecanismo de aprendizagem está presente. Número entre parênteses representa percentual em relação ao total de institutos da amostra]

Processos e mecanismos de compartilhamento de conhecimento

$\begin{array}{ccc}\text { Fase } & \text { Fase } & \text { Fase } \\ \text { Inicial } & \text { Intermediária } & \text { Atual }\end{array}$

1. Intercâmbio com clientes para o desenvolvimento de projetos (nacionais)

$13(72,2) \quad 15(83,3) \quad 17(94,4)$

2. Intercâmbio com clientes para o desenvolvimento de projetos (internacionais)

$8(44,4) \quad 11(61,1) \quad 15(83,3)$

3. Intercâmbio com parceiros para o desenvolvimento de projetos (nacionais)

$13(72,2) \quad 15(83,3) \quad 17(94,4)$

4. Intercâmbio com parceiros para o desenvolvimento de projetos (internacionais)

$8(72,2)$

$11(61,1) \quad 15(83,3)$

5. Interação com matriz, filiais, sócio-fundadores

$9(50,0) \quad 10(55,5) \quad 14(77,7)$

6. Encontros de projeto no instituto

$15(83,3) \quad 15(83,3) \quad 18(100,0)$

7. Encontros de projeto na matriz e/ou no cliente

$10(55,5)$

$13(72,2) \quad 18(100,0)$

8. Comitê da qualidade

$6(33,3)$

$8(44,4) \quad 12(66,6)$

9. Visitas a instituições no exterior (empresas, universidades e institutos de P\&D)

$11(61,1)$

$12(66,6) \quad 16(88,8)$

10. Desenvolvimento de protótipos

$10(55,5) \quad 10(55,5) \quad 17(94,4)$

11. Times de trabalho multifuncionais e multidisciplinares

$12(66,6) \quad 13(72,2) \quad 16(88,8)$

12. Task-forces

$11(61,1)$

$13(72,2) \quad 17(94,4)$

13. Compartilhamento de dados em rede interna

$11(61,1) \quad 14(77,7) \quad 18(100,0)$

14. Comunicação convencional (quadros de avisos, murais)

$14(77,7) \quad 15(83,3) \quad 18(100,0)$

15. Modalidades de comunicação dinâmica (e-mail, internet, intranet)

$10(55,5) \quad 17(94,4) \quad 18(100,0)$

Processos e mecanismos de aquisição interna de conhecimento

16. Códigos e padrões de engenharia

$8(44,4) \quad 10(55,5) \quad 14(77,7)$

17. Soluções modulares para projetos

$8(44,4) \quad 11(61,1) \quad 16(88,8)$

18. Normas e regulamentos (comunicações internas e memorandos)

$13(72,2) \quad 14(77,7) \quad 18(100,0)$

19. Elaboração de procedimentos e instruções técnicas

$11(61,1) \quad 12(66,6) \quad 17(94,4)$

20. Processo de certificação pela ISO $(9000,9001,14000,17025)$

21. Processo de certificação CMM

$4(22,2) \quad 5(27,7) \quad 10(55,5)$

$2(11,1) \quad 2(11,1) \quad 6(33,3)$

22. Registros de treinamentos

$8(44,4) \quad 10(55,5) \quad 14(77,7)$

23. Sistemas de Controle de Documentos e Administração de Contratos

$13(72,2) \quad 14(77,7) \quad 17(94,4)$

24. Instruções técnicas e ferramentas específicas para projetos

$13(72,2) \quad 13(72,2) \quad 15(83,3)$

Fonte: derivado da pesquisa de campo. 
foi encontrada na metade dos institutos examinados. Há, entretanto, institutos que, mesmo não certificados oficialmente à base de CMM, seguem as especificações da certificação, principalmente em níveis um e dois. Na fase atual, há seis $(33,3 \%)$ institutos oficialmente certificados pelo CMM, todos nos níveis CMM2 ou CMM3. Tal evidência confirma a limitação da certificação CMM como métrica isolada de capacidade tecnológica.

\subsection{Ligações entre os institutos da amostra e outras organizações do sistema de inovação ${ }^{14}$}

Foram encontrados um total de 1.767 ligações estabelecidas entre institutos da amostra e os demais componentes do sistema de inovação. Como mostrado na Figura 1, as ligações informais e as ligações formais são as que apresentam maior incidência respondendo, respectivamente, por $700(39,62 \%)$ e 759 (42,95\%) do total de ligações estabelecidas. Quanto às ligações voltadas para a educação e treinamento de recursos humanos, estas correspondem a 308 $(17,43 \%)$ do total de ligações existentes.

\section{FIGURA 1}

Distribuição da incidência dos tipos de ligações encontradas nos institutos da amostra

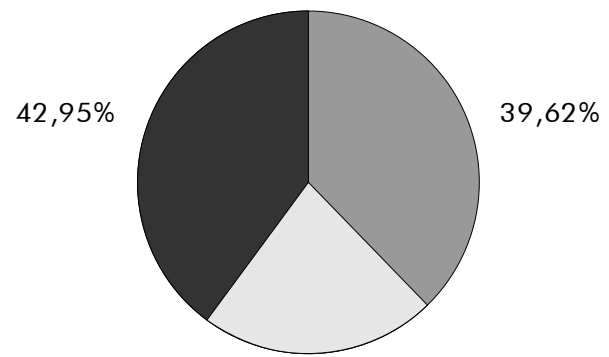

$17,43 \%$ 
TABELA 8

Natureza das ligações vs. tipos de organização do sistema de inovação

\begin{tabular}{|c|c|c|c|c|c|c|}
\hline \multirow[t]{2}{*}{ Tipo de Ligação } & \multicolumn{6}{|c|}{ Tipo de Instituição } \\
\hline & $\begin{array}{l}\text { Instituto de } \\
\text { Pesquisa }\end{array}$ & Universidade & Empresa & $\begin{array}{c}\text { Órgãos do } \\
\text { governo }\end{array}$ & Outros & Total \\
\hline $\begin{array}{l}\text { Ligações } \\
\text { informais }\end{array}$ & $\begin{array}{c}149 \\
(21,29 \%)\end{array}$ & $\begin{array}{c}298 \\
(42,57 \%)\end{array}$ & $\begin{array}{c}204 \\
(29,14 \%)\end{array}$ & $\begin{array}{c}29 \\
(4,14 \%)\end{array}$ & $\begin{array}{c}20 \\
(2,86 \%)\end{array}$ & $\begin{array}{c}700 \\
(100,00 \%)\end{array}$ \\
\hline $\begin{array}{l}\text { Ligações à base } \\
\text { de formação de } \\
\text { recursos humanos }\end{array}$ & $\begin{array}{c}48 \\
(15,59 \%)\end{array}$ & $\begin{array}{c}144 \\
(46,75 \%)\end{array}$ & $\begin{array}{c}105 \\
(34,09 \%)\end{array}$ & $\begin{array}{c}8 \\
(2,60 \%)\end{array}$ & $\begin{array}{c}3 \\
(0,97 \%)\end{array}$ & $\begin{array}{c}308 \\
(100,00 \%)\end{array}$ \\
\hline $\begin{array}{l}\text { Ligações } \\
\text { formais }\end{array}$ & $\begin{array}{c}141 \\
(18,58 \%)\end{array}$ & $\begin{array}{c}188 \\
(24,77 \%)\end{array}$ & $\begin{array}{c}393 \\
(51,78 \%)\end{array}$ & $\begin{array}{c}31 \\
(4,08 \%)\end{array}$ & $\begin{array}{c}6 \\
(0,79 \%)\end{array}$ & $\begin{array}{c}759 \\
(100,00 \%)\end{array}$ \\
\hline Total & $\begin{array}{c}338 \\
(19,13 \%)\end{array}$ & $\begin{array}{c}630 \\
(35,65 \%)\end{array}$ & $\begin{array}{c}702 \\
(39,73 \%)\end{array}$ & $\begin{array}{c}68 \\
(3,85 \%)\end{array}$ & $\begin{array}{c}29 \\
(1,64 \%)\end{array}$ & $\begin{array}{c}1.767 \\
(100,00 \%)\end{array}$ \\
\hline
\end{tabular}

Fonte: derivado da pesquisa de campo.

A natureza das ligações (informais, de recursos humanos e formais) que os institutos pesquisados mantêm com outras organizações é apresentada na Tabela 8. No total, as ligações estabelecidas com outros institutos de pesquisa representam 19,13\% dos casos, enquanto as ligações estabelecidas com universidades e empresas respondem, respectivamente, por $35,65 \%$ e $39,73 \%$ do total de ligações estabelecidos.

No que se refere às ligações estabelecidas com órgãos governamentais foram encontradas 68 ligaçóes, como por exemplo: Serviço de Apoio a Micro e Pequena Empresa (SEBRAE) (18 ligações), Financiadora de Estudos e Projetos (FINEP) (10 ligações) e Conselho Nacional de Desenvolvimento Científico e Tecnológico (CNPq) (oito ligações). Além disso, há, ainda, ligações que são constituídas com outros agentes, ${ }^{15}$ tais como agências internacionais de fomento e incubadoras de empresas, as quais correspondem a $1,64 \%$ do total de ligações estabelecidas.

\footnotetext{
15 A designação "outros" refere-se a certos tipos de ligações e tipos de organizações não especificados na classificação e terminologia apresentados nas Tabelas 3 e 4 . Optou-se por manter esta designação, pois ela envolve ligações pontuais e que, durante o período trabalho de campo deste estudo, inda se encontravam em fase de desenvolvimento.
} 
As evidências sugerem que a maior parte das ligaçōes informais e de recursos humanos foi estabelecida com universidades, isto é, $42,6 \%$ e $46,7 \%$, respectivamente. De acordo com um dos entrevistados: "As universidades são centros de excelência, que, por conta de suas atividades (ensino e pesquisa), costumam estar em sintonia com o desenvolvimento tecnológico mundial e até mesmo à frente do que as empresas vêm desenvolvendo". Entrevistas nos institutos pesquisados indicaram que a relação com universidades é vista como uma maneira de tais institutos manterem seus conhecimentos direta e indiretamente atualizados - seja pelo contato com pesquisadores, pela participação em seminários e conferências ou pelo recrutamento de profissionais qualificados. Portanto, os institutos utilizam as universidades como importante apoio (e fonte de conhecimento) para as suas atividades tecnológicas inovadoras. Adicionalmente, o contato com as universidades, segundo um dirigente de um dos institutos da amostra, "tem sido útil para auxiliar-nos na estruturação de nossas idéias e projetos. Por meio do contato freqüente com a academia nos beneficiamos também em termos de aprimoramento de disciplina e método de pensamento e questionamento". Esta evidência, por sua vez, alinha-se a perspectiva de Nelson (1992) sobre a relação entre universidade e "indústria”.

No que se refere às ligaçôes formais, as empresas aparecem como os parceiros preferenciais, sendo responsáveis por $51,78 \%$ das ligaçóes dessa natureza. As evidências indicam que tal fato se dá, em grande medida, por conta dos projetos de solução de problemas em resposta a demanda pelas empresas clientes.

Por exemplo, vale mencionar aqui "consórcio tecnológico" como uma das estratégias de inovação implementadas pelo Instituto Genius de Tecnologia pode ser utilizado como um exemplo da relação que os institutos vêm buscando estabelecer tanto com universidades quanto com empresas. A estrutura de "consórcio tecnológico" é representada pela união de esforços do Genius com universidades e empresas (consórcio tecnológico = universidades + Genius + empresas). Nessa estrutura, cabe às empresas a demanda por projetos, enquanto o Genius fica responsável pelo desenvolvimento dos mesmos. A partir da demanda empresarial, o Genius contacta as universidades parceiras, com o objetivo de fortalecer e complementar sua capacidade tecnológica, somando os conhecimentos repassados pelas universidades. ${ }^{16}$

16 Ver estudo sobre a experiência do Instituto Genius de Tecnologia, uma típica OSIC, em Figueiredo \& Vedovello (2005). 
Ainda em termos de tipos de organizações com as quais as ligações são estabelecidas, cabe ressaltar o baixo número de ligações estabelecidas entre os institutos estudados Como mencionado por dirigente entrevistado, seria interessante que os institutos buscassem fortalecer suas interações entre si, visando ao compartilhamento de experiências (ou mesmo de recursos), à execução de tarefas conjuntas e complementares e à otimização dos recursos existentes (em termos humanos, financeiros e materiais).

É importante destacar, entretanto, que baixa a incidência de relações entre os institutos não necessariamente significa que os resultados e/ou os benefícios provenientes das ligações sejam fracos. Os institutos independentes, inclusive, vêm realizando encontros mensais, onde procuram traçar seus objetivos comuns, unindo esforços para pleiteá-los conjuntamente em entidades governamentais tais como o MCT e a FINEP, por exemplo. Como afirmado por um dos entrevistados: "a união dos institutos nos dá maior representatividade junto ao governo e, assim, facilita que nossos interesses sejam ouvidos e atendidos".

\subsubsection{Ligações informais}

A Tabela 9 apresenta a incidência de ligações informais de forma desagregada, considerando-se o número total de 700 ligações encontradas. Os contatos informais com pesquisadores e empresários, à primeira vista, podem parecer irrelevante dada a sua simplicidade. Entretanto, é importante salientar que é a partir de contatos informais que todos os outros tipos de ligação têm a possibilidade de ocorrer. Essa ligação significa, antes de tudo, uma primeira abordagem, uma identificação inicial das capacidades e necessidades de cada parceiro no processo de interação.

A Tabela 10 apresenta evidências relativas aos tipos de componentes do sistema de inovação com as quais os institutos examinados estabelecem suas interaçôes informais. As ligações informais que são estabelecidas com universidades representam $42,43 \%$ do total de ligações dessa natureza, sendo seguidas pelas ligações estabelecidas com empresas $(29,14 \%)$, com outros institutos de pesquisa $(21,29 \%)$ e, por fim, com órgãos do governo $(4,29 \%)$.

Cabe ainda destacar, no caso das ligações entre os institutos de pesquisa, o percentual das ligaçôes - na forma de acesso a pesquisas de departamentos 
TABELA 9

Incidência de ligações informais nos institutos estudados

Ligações Informais

Incidência

Contatos informais com pesquisadores / empresários

Acesso à literatura especializada

Acessos à pesquisa de departamentos específicos

Participação em seminários e conferências

Acessos a equipamentos da universidade e/ou dos

Fonte: derivado da pesquisa de campo.

específicos (16,83\%) e acesso a equipamentos (16,49\%) - são relativamente baixos frente a incidência das ligaçôes com universidades (46,53\% e 39,18\%) e empresas $(31,68 \%$ e $43,30 \%)$. As ligações estabelecidas com órgãos do governo são inferiores a $6 \%$ no caso de todas as ligações informais.

\subsubsection{Ligações de recursos humanos}

A incidência das ligações de recursos humanos realizadas pelos institutos analisados são apresentadas na Tabela 11. Dentre as ligaçôes de recursos humanos, há o predomínio dos programas de treinamento formalmente organizados, que responde por 30,84\% dos casos. Em seguida, destacam-se as ligações envolvimento de estudantes em projetos industriais $(23,70 \%)$ e recrutamento de recém-graduados $(23,05 \%)$. De acordo com um entrevistado em um dos institutos da amostra, "profissionais recém-graduados tendem a responder de maneira muito criativa às atividades de desenvolvimento de software”. 
TABELA 10

Incidência de ligações informais vs. tipos de organização do sistema de inovação

\begin{tabular}{|c|c|c|c|c|c|c|}
\hline \multirow[t]{2}{*}{ Tipo de Ligação } & \multicolumn{6}{|c|}{ Tipo de Instituição } \\
\hline & $\begin{array}{l}\text { Instituto de } \\
\text { Pesquisa }\end{array}$ & Universidade & Empresa & $\begin{array}{l}\text { Órgãos do } \\
\text { Gorverno }\end{array}$ & Outros & Total \\
\hline $\begin{array}{l}\text { Contatos informais com } \\
\text { pesquisadores / empresários }\end{array}$ & $\begin{array}{c}36 \\
(22,93 \%)\end{array}$ & $\begin{array}{c}73 \\
(46,50 \%)\end{array}$ & $\begin{array}{c}34 \\
(21,66 \%)\end{array}$ & $\begin{array}{c}8 \\
(5,10 \%)\end{array}$ & $\begin{array}{c}6 \\
(3,81 \%)\end{array}$ & $\begin{array}{c}157 \\
(100,00 \%)\end{array}$ \\
\hline $\begin{array}{l}\text { Acesso à literatura } \\
\text { especializada }\end{array}$ & $\begin{array}{c}17 \\
(19,32 \%)\end{array}$ & $\begin{array}{c}43 \\
(48,86 \%)\end{array}$ & $\begin{array}{c}19 \\
(21,59 \%)\end{array}$ & $\begin{array}{c}5 \\
(5,68 \%)\end{array}$ & $\begin{array}{c}4 \\
(4,55 \%)\end{array}$ & $\begin{array}{c}88 \\
(100,00 \%)\end{array}$ \\
\hline $\begin{array}{l}\text { Acessos à pesquisa de } \\
\text { departamentos específicos }\end{array}$ & $\begin{array}{c}17 \\
(16,83 \%)\end{array}$ & $\begin{array}{c}47 \\
(46,53 \%)\end{array}$ & $\begin{array}{c}32 \\
(31,68 \%)\end{array}$ & $\begin{array}{c}4 \\
(3,97 \%)\end{array}$ & $\begin{array}{c}1 \\
(0,99 \%)\end{array}$ & $\begin{array}{c}101 \\
(100,00 \%)\end{array}$ \\
\hline $\begin{array}{l}\text { Participação em seminários } \\
\text { e conferências }\end{array}$ & $\begin{array}{c}31 \\
(23,31 \%)\end{array}$ & $\begin{array}{c}59 \\
(44,36 \%)\end{array}$ & $\begin{array}{c}32 \\
(24,06 \%)\end{array}$ & $\begin{array}{c}6 \\
(4,51 \%)\end{array}$ & $\begin{array}{c}5 \\
(3,76 \%)\end{array}$ & $\begin{array}{c}133 \\
(100,00 \%)\end{array}$ \\
\hline $\begin{array}{l}\text { Acessos a equipamentos da } \\
\text { universidade e/ou dos institutos } \\
\text { de pesquisa e/ou das empresas }\end{array}$ & $\begin{array}{c}16 \\
(16,49 \%)\end{array}$ & $\begin{array}{c}38 \\
(39,18 \%)\end{array}$ & $\begin{array}{c}42 \\
(43,30 \%)\end{array}$ & $\begin{array}{c}1 \\
(1,03 \%)\end{array}$ & $\begin{array}{c}0 \\
(0,00 \%)\end{array}$ & $\begin{array}{c}97 \\
(100,00 \%)\end{array}$ \\
\hline $\begin{array}{l}\text { Participação em programas } \\
\text { espećíficos }\end{array}$ & $\begin{array}{c}26 \\
(22,22 \%)\end{array}$ & $\begin{array}{c}37 \\
(31,62 \%)\end{array}$ & $\begin{array}{c}45 \\
(38,46 \%)\end{array}$ & $\begin{array}{c}6 \\
(5,14 \%)\end{array}$ & $\begin{array}{c}3 \\
(2,56 \%)\end{array}$ & $\begin{array}{c}117 \\
(100,00 \%)\end{array}$ \\
\hline Outras ligações informais & $\begin{array}{c}6 \\
(85,71 \%)\end{array}$ & $\begin{array}{c}0 \\
(0,00 \%)\end{array}$ & $\begin{array}{c}0 \\
(0,00 \%)\end{array}$ & $\begin{array}{c}0 \\
(0,00 \%)\end{array}$ & $\begin{array}{c}1 \\
(14,29 \%)\end{array}$ & $\begin{array}{c}7 \\
(100,00 \%)\end{array}$ \\
\hline Total & $\begin{array}{c}149 \\
(21,29 \%)\end{array}$ & $\begin{array}{c}297 \\
(42,43 \%)\end{array}$ & $\begin{array}{c}204 \\
(29,14 \%)\end{array}$ & $\begin{array}{c}30 \\
(4,29 \%)\end{array}$ & $\begin{array}{c}20 \\
(2,85 \%)\end{array}$ & $\begin{array}{c}700 \\
(100,00 \%)\end{array}$ \\
\hline
\end{tabular}

Fonte: derivado da pesquisa de campo.

Em termos de outras ligações de recursos humanos, cabe destacar a realização de intercâmbios de estudantes de pós-graduação em nível de especialização, mestrado e doutorado. Chama a atenção o fato de o recrutamento de cientistas e engenheiros mais experientes ser a ligação de menor incidência $(17,53 \%)$. É importante salientar que tal fato não necessariamente reflete ausência de atividades tecnológicas sofisticadas nesses institutos. Entretanto, como afirmado por pelo menos três dirigentes entrevistados, uma atitude mais pró-ativa dos institutos estudados - principalmente aqueles independentes e/ou ligados a empresas, onde ainda é baixo o número de engenheiros 
TABELA 11

Incidência das ligações à base de formação de recursos humanos nos institutos estudados

$\begin{array}{lc}\text { Recursos humanos } & \text { Incidência } \\ \text { Envolvimento de estudantes em projetos } & 73 \\ \text { Recrutamento de recém-graduados } & (23,70 \%) \\ & (23,05 \%) \\ \text { Recrutamento de cientistas e engenheiros mais experientes } & 54 \\ & (17,53 \%) \\ \text { Programas de treinamento formalmente organizados } & 95 \\ & (30,84 \%) \\ \text { Ouras ligações de recursos humanos } & 15 \\ & (4,88 \%) \\ \text { Total } & 308\end{array}$

Fonte: derivado da pesquisa de campo.

especializados - no que se refere ao recrutamento de pessoal mais qualificado poderá garantir um melhor desempenho inovador no futuro. ${ }^{17}$

Em termos das organizações com as quais os institutos examinados estabelecem as ligaçõos de recursos humanos, a Tabela 12 mostra a predominância das parcerias com universidades, que responde por 46,43\% das ligações de recursos humanos estabelecidos. No entanto, a ligação de maior incidência programas de treinamento formalmente organizados - ocorre $45,43 \%$ das vezes com empresas e não com universidades. Ainda no caso dos programas de treinamento formalmente organizados, cabe frisar que os institutos de pesquisa funcionam tanto como fornecedores e receptores de programas de formação de recursos humanos. Esta evidência alinha-se a Bell e Pavitt $(1993,1993)$ e Figueiredo (2001) que argumentam que não apenas as universidades, mas também, e cada vez mais, as empresas (organizações industriais de manufatura e serviços) são entidades geradoras de conhecimento.

$\mathrm{Na}$ posição de receptores de programa de treinamento, os institutos

\footnotetext{
17 Isto não significa que tais profissionais sejam necessariamente PhDs. O que se observa neste setor industrial é que, como afirmado acima, profissionais recém-formados tendem a engajar-se em atividades tecnológicas criativas. Não obstante, há a necessidade de um número substancial de especialistas em técnicas específicas de desenvolvimento de serviços de software.
} 
TABELA 12

Incidência de ligações de formação de recursos humanos vs. tipos de organização do sistema de inovação

\begin{tabular}{|c|c|c|c|c|c|c|}
\hline \multirow[t]{2}{*}{ Tipo de Ligação } & \multicolumn{6}{|c|}{ Tipo de Instituição } \\
\hline & $\begin{array}{l}\text { Instituto de } \\
\text { Pesquisa }\end{array}$ & Universidade & Empresa & $\begin{array}{l}\text { Órgãos do } \\
\text { Gorverno }\end{array}$ & Outros & Total \\
\hline $\begin{array}{l}\text { Envolvimento de } \\
\text { estudantes em projetos }\end{array}$ & $\begin{array}{c}10 \\
(13,70 \%)\end{array}$ & $\begin{array}{c}37 \\
(50,68 \%)\end{array}$ & $\begin{array}{c}25 \\
(34,25 \%)\end{array}$ & $\begin{array}{c}1 \\
(1,37 \%)\end{array}$ & $\begin{array}{c}0 \\
(0,00 \%)\end{array}$ & $\begin{array}{c}73 \\
(100,00 \%)\end{array}$ \\
\hline $\begin{array}{l}\text { Recrutamento de } \\
\text { recém-graduados }\end{array}$ & $\begin{array}{c}6 \\
(8,45 \%)\end{array}$ & $\begin{array}{c}42 \\
(59,15 \%)\end{array}$ & $\begin{array}{c}22 \\
(30,99 \%)\end{array}$ & $\begin{array}{c}1 \\
(1,41 \%)\end{array}$ & $\begin{array}{c}0 \\
(0,00 \%)\end{array}$ & $\begin{array}{c}71 \\
(100,00 \%)\end{array}$ \\
\hline $\begin{array}{l}\text { Recrutamento de cientistas e } \\
\text { engenheiros mais experientes }\end{array}$ & $\begin{array}{c}7 \\
(12,96 \%)\end{array}$ & $\begin{array}{c}31 \\
(57,41 \%)\end{array}$ & $\begin{array}{c}15 \\
(27,78 \%)\end{array}$ & $\begin{array}{c}1 \\
(1,85 \%)\end{array}$ & $\begin{array}{c}0 \\
(0,00 \%)\end{array}$ & $\begin{array}{c}54 \\
(100,00 \%)\end{array}$ \\
\hline $\begin{array}{l}\text { Programas de treinamento } \\
\text { formalmente organizados }\end{array}$ & $\begin{array}{c}22 \\
(23,16 \%)\end{array}$ & $\begin{array}{c}24 \\
(25,26 \%)\end{array}$ & $\begin{array}{c}43 \\
(45,26 \%)\end{array}$ & $\begin{array}{c}3 \\
(3,16 \%)\end{array}$ & $\begin{array}{c}3 \\
(3,16 \%)\end{array}$ & $\begin{array}{c}95 \\
(100,00 \%)\end{array}$ \\
\hline $\begin{array}{l}\text { Outras ligações de } \\
\text { recursos humanos }\end{array}$ & $\begin{array}{c}3 \\
(20,00 \%)\end{array}$ & $\begin{array}{c}9 \\
(60,00 \%)\end{array}$ & $\begin{array}{c}0 \\
(0,00 \%)\end{array}$ & $\begin{array}{c}3 \\
(20,00 \%)\end{array}$ & $\begin{array}{c}0 \\
(0,00 \%)\end{array}$ & $\begin{array}{c}15 \\
(100,00 \%)\end{array}$ \\
\hline Total & $\begin{array}{c}48 \\
(15,58 \%)\end{array}$ & $\begin{array}{c}143 \\
(46,43 \%)\end{array}$ & $\begin{array}{c}105 \\
(34,09 \%)\end{array}$ & $\begin{array}{c}9 \\
(2,93 \%)\end{array}$ & $\begin{array}{c}3 \\
(0,97 \%)\end{array}$ & $\begin{array}{c}308 \\
(100,00 \%)\end{array}$ \\
\hline
\end{tabular}

Fonte: derivado da pesquisa de campo.

recebem treinamento direto das empresas, o que costuma acontecer antes do desenvolvimento de projetos para atender a demandas empresariais específicas. Por exemplo, no Centro de Ciências e Tecnologia da Universidade Federal de Campina Grande (CCT/UFCG) os colaboradores alocados nos projetos para a Motorola passaram por um período de treinamento, realizado por profissionais da empresa, em gestão de projetos, melhoria de processos, CMM e tecnologia iDEN.

Por outro lado, na posição de fornecedores de treinamento, os institutos ficam responsáveis pela execução prática de serviços de treinamento inicialmente concebidos por empresas. Por exemplo, do Instituto Eldorado que, durante quatro anos, participou do Programa de Capacitação Tecnológica (PCT), desenvolvido também pela Motorola, realizou programas de formação em 15 universidades brasileiras. O PCT foi implementado pela Motorola no intuito 
de suprir as deficiências na formação dos recursos humanos no Brasil em processos e software. Inicialmente, foram selecionadas as áreas-chave para empresa (processos, protocolo, wireless e embedded software). Em seguida, foram identificadas as universidades que desenvolviam atividades relevantes nessas áreas.

A Motorola, então, firmou parceria com as mesmas, oferecendo a estas serviços de treinamento. Paralelamente, a Motorola estimulou tais universidades a implementarem mudanças em seus currículos os quais ainda careciam de mais ênfase em certas áreas de impacto prático, como por exemplo, a gestão de processos de desenvolvimento de software. Essa evidência mostra, de um lado, a pró-atividade de uma empresa (transnacional) em provocar mudanças em um aspecto específico do sistema de inovação de um país, neste caso, qualidade da formação universitária. De outro, mostra ainda como o sistema local de inovação (em nível de Brasil) pode beneficiar-se da presença e papel ativo de empresas transnacionais em sua economia. Esse papel pró-ativo de uma subsidiária de empresa transnacional alinha, por sua vez, às evidências encontradas na Malásia (Ariffin \& Bell, 1999; Ariffin, 2000). O comentário de um dirigente universitário entrevistado reflete a repercussão positiva da iniciativa dessa empresa: "não basta que o aluno saiba conceber um excelente algoritmo; é preciso aprender os princípios de um projeto e processo de desenvolvimento de software; é isso que se ensina em nível internacional”.

\subsubsection{Ligações formais}

Como mostrado na Tabela 13, as ligações formais representam o grupo de ligaçôes com maior incidência (759 casos) dentre as ligações estabelecidas pelos institutos analisados. Em termos das ligações que compóem esse grupo de ligações, os de maior incidência são os estabelecimentos de contratos de pesquisa e de pesquisa conjunta, que, somados, correspondem a cerca de $50 \%$ das incidências. Em terceiro, aparece consultoria (16,86\%). Os serviços de atualização de acervo representam apenas 4,74\% das ligações formais estabelecidas.

As evidências indicam que os projetos de pesquisa desenvolvidos com ou para empresas, em um primeiro momento, são projetos simples. Segundo um entrevistado, os primeiros projetos "funcionam como um 'quebra-gelo' 
TABELA 13

Incidência de ligações formais nos institutos da amostra

\begin{tabular}{lc}
\hline Ligações formais & Incidência \\
Consultoria desenvolvida por pesquisadores ou consultores & 128 \\
Análises e testes & $(16,86 \%)$ \\
Serviços de atualização de acervo & 100 \\
Respostas técnicas & $(13,18 \%)$ \\
& 36 \\
Estabelecimento de contratos de pesquisa & $(4,74 \%)$ \\
& 97 \\
Estabelecimento de pesquisa conjunta & $(12,78 \%)$ \\
Outras ligações formais & 200 \\
Total & $(26,35 \%)$ \\
& 174 \\
& $(22,93 \%)$ \\
\end{tabular}

Fonte: derivado da pesquisa de campo.

e ajudam a estabelecer uma confiança mútua entre a empresa cliente e o instituto". Estabelecida essa relação de confiança, os desafios lançados pelas empresas tornam-se crescentes.

Há casos, no entanto, em que projetos desafiadores são estabelecidos desde o início do relacionamento. Como exemplo, pode-se mencionar o Instituto Eldorado, onde os primeiros projetos foram desenvolvidos para a Motorola e, nas palavras de um colaborador do instituto, "nunca houve nada de trivial".

Em termos das organizações com as quais tais ligações são realizadas, a Tabela 14 mostra que a maioria das interações formais acontece com empresas, com as quais os institutos analisados estabelecem 51,78\% das ligações dessa natureza. Há, entretanto, ligaçóes que são estabelecidos em considerável proporção com universidades (pesquisa conjunta $(47,70 \%)$ ) e institutos de pesquisa (serviços de atualização de acervo $(38,89 \%)$ ). Curiosamente, esse último tipo de ligação é estabelecido na mesma proporção com universidades e órgãos do governo $(11,11 \%)$. 
TABELA 14

Ligações formais vs. tipo de organização do sistema de inovação

\begin{tabular}{|c|c|c|c|c|c|c|}
\hline \multirow[t]{2}{*}{ Tipo de Ligação } & \multicolumn{6}{|c|}{ Tipo de Instituição } \\
\hline & $\begin{array}{l}\text { Instituto de } \\
\text { Pesquisa }\end{array}$ & Universidade & Empresa & $\begin{array}{l}\text { Órgãos do } \\
\text { Gorverno }\end{array}$ & Outros & Total \\
\hline $\begin{array}{l}\text { Consultoria desenvolvida por } \\
\text { pesquisadores ou consultores }\end{array}$ & $\begin{array}{c}27 \\
(21,09 \%)\end{array}$ & $\begin{array}{c}25 \\
(19,53 \%)\end{array}$ & $\begin{array}{c}70 \\
(54,69 \%)\end{array}$ & $\begin{array}{c}5 \\
(3,91 \%)\end{array}$ & $\begin{array}{c}1 \\
(0,78 \%)\end{array}$ & $\begin{array}{c}128 \\
(128,00 \%)\end{array}$ \\
\hline Análises e teses & $\begin{array}{c}18 \\
(18,00 \%)\end{array}$ & $\begin{array}{c}13 \\
(13,00 \%)\end{array}$ & $\begin{array}{c}67 \\
(67,00 \%)\end{array}$ & $\begin{array}{c}2 \\
(2,00 \%)\end{array}$ & $\begin{array}{c}0 \\
(0,00 \%)\end{array}$ & $\begin{array}{c}100 \\
(100,00 \%)\end{array}$ \\
\hline $\begin{array}{l}\text { Serviços de atualização } \\
\text { de acervo }\end{array}$ & $\begin{array}{c}14 \\
(38,89 \%)\end{array}$ & $\begin{array}{c}4 \\
(11,11 \%)\end{array}$ & $\begin{array}{c}13 \\
(36,11 \%)\end{array}$ & $\begin{array}{c}4 \\
(11,11 \%)\end{array}$ & $\begin{array}{c}1 \\
(2,78 \%)\end{array}$ & $\begin{array}{c}36 \\
(100,00 \%)\end{array}$ \\
\hline Respostas técnicas & $\begin{array}{c}17 \\
(17,53 \%)\end{array}$ & $\begin{array}{c}10 \\
(10,31 \%)\end{array}$ & $\begin{array}{c}67 \\
(69,07 \%)\end{array}$ & $\begin{array}{c}3 \\
(3,09 \%)\end{array}$ & $\begin{array}{c}0 \\
(0,00 \%)\end{array}$ & $\begin{array}{c}97 \\
(100,00 \%)\end{array}$ \\
\hline $\begin{array}{l}\text { Estabelecimento de contratos } \\
\text { de pesquisa }\end{array}$ & $\begin{array}{c}33 \\
(16,50 \%)\end{array}$ & $\begin{array}{c}51 \\
(25,50 \%)\end{array}$ & $\begin{array}{c}105 \\
(52,50 \%)\end{array}$ & $\begin{array}{c}11 \\
(5,50 \%)\end{array}$ & $\begin{array}{c}0 \\
(0,00 \%)\end{array}$ & $\begin{array}{c}200 \\
(100,00 \%)\end{array}$ \\
\hline $\begin{array}{l}\text { Estabelecimento de } \\
\text { pesquisa conjunta }\end{array}$ & $\begin{array}{c}28 \\
(16,09 \%)\end{array}$ & $\begin{array}{c}83 \\
(47,70 \%)\end{array}$ & $\begin{array}{c}54 \\
(31,03 \%)\end{array}$ & $\begin{array}{c}6 \\
(3,46 \%)\end{array}$ & $\begin{array}{c}3 \\
(1,72 \%)\end{array}$ & $\begin{array}{c}174 \\
(100,00 \%)\end{array}$ \\
\hline Outras ligações formais & $\begin{array}{c}4 \\
(16,67 \%)\end{array}$ & $\begin{array}{c}2 \\
(8,33 \%)\end{array}$ & $\begin{array}{c}17 \\
(70,83 \%)\end{array}$ & $\begin{array}{c}0 \\
(0,00 \%)\end{array}$ & $\begin{array}{c}1 \\
(4,17 \%)\end{array}$ & $\begin{array}{c}24 \\
(100,00 \%)\end{array}$ \\
\hline Total & $\begin{array}{c}141 \\
(18,58 \%)\end{array}$ & $\begin{array}{c}188 \\
(24,77 \%)\end{array}$ & $\begin{array}{c}393 \\
(51,78 \%)\end{array}$ & $\begin{array}{c}31 \\
(4,08 \%)\end{array}$ & $\begin{array}{c}6 \\
(0,79 \%)\end{array}$ & $\begin{array}{c}759 \\
(100,00 \%)\end{array}$ \\
\hline
\end{tabular}

Fonte: derivado da pesquisa de campo.

De fato, as evidências indicam que as ligações formais acontecem, em sua maioria com empresas. Os institutos também iniciam grande parte de suas ligações formais com empresas. De um lado, esse dado parece refletir o fato de alguns institutos da amostra terem nascido a partir de spin-offs de empresas: três dos mais inovadores institutos da amostra são spin-offs (dois de empresa uma brasileira e outra estrangeira) e um universidade. Porém, pelo menos nessa amostra examinada, os institutos que foram criados por empresas que aproveitaram o arcabouço institucional de incentivo às atividades de P\&D (Lei de Informática), há muito deixaram de ter a sua empresa criadora como seu único e exclusivo usuário. As observações diretas e as entrevistas durante os trabalhos de campo, mostraram que, pelo menos nesta amostra, os institutos têm adotado uma gestão profissional, orientada a resultados e à base de uma carteira diversificada de clientes. Por exemplo, dois institutos da amostra fornecem serviços a empresas que são competidoras daquela que, há alguns anos, os criou. 


\subsubsection{Resultados das ligações estabelecidas pelos institutos da amostra}

Quanto aos resultados obtidos das ligações, cabe frisar que uma ligação pode apresentar mais de um resultado. Por isso, foram encontrados 6.127 resultados das ligações estabelecidas. Tais resultados, por sua vez, derivam de um total de 1.767 ligaçóes encontradas. Como mostrado na Figura 2, a maior incidência está relacionada à implementação de programas de base $(1.428(80,8 \%))$, ao fornecimento de informações $(1.246(70,5 \%))$ e à geração de relatórios $(1.214$ $(68,7 \%)$. Por outro lado, os resultados em termos de patentes é relativamente inferior $(117(6,6 \%))$. É interessante destacar que os benefícios gerados a partir de uma ligação podem gerar externalidades, beneficiando outras ligaçōes, que podem ou não ser da mesma natureza. Certamente, uma das limitações deste estudo é o fato de não ter explorado a relação entre os resultados das ligações e os níveis de capacidade tecnológica. Por meio do exame dessa relação, poderíamos obter uma noção mais concreta dos benefícios de cada tipo e nível de capacidade tecnológica para os resultados que emergem dessas ligações.

FIGURA 2

Incidência dos resultados das ligações estabelecidas pelos institutos da amostra

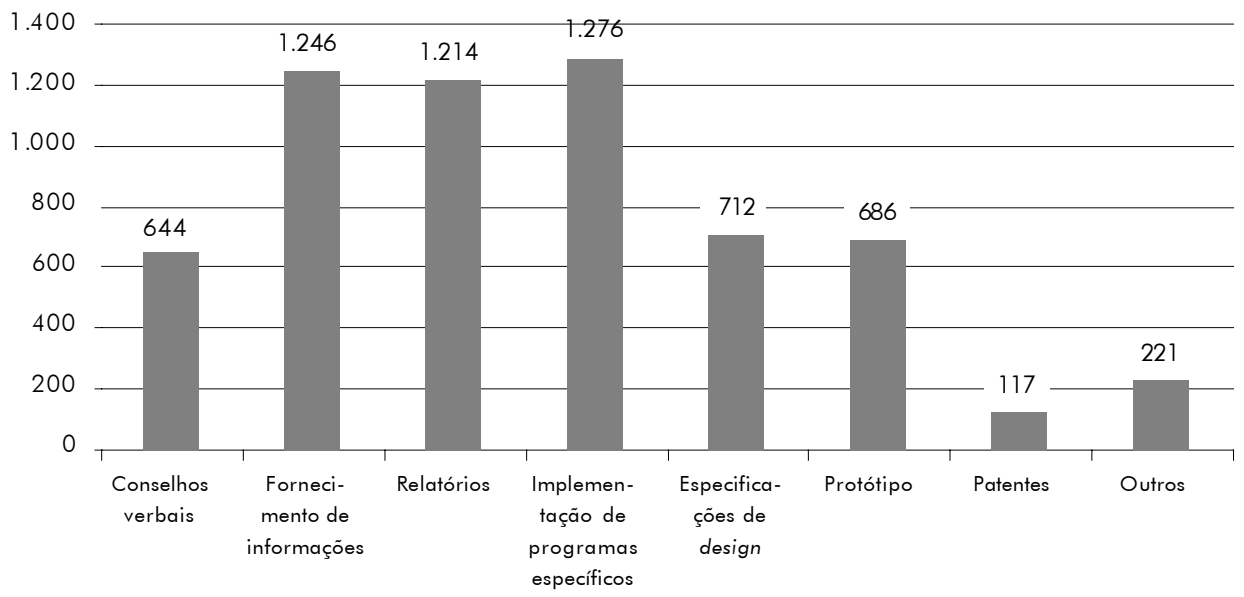

Fonte: dados da pesquisa de campo. 


\section{Discussões, conclusões e recomendações}

Este artigo examinou tipos e níveis de capacidade tecnológica, bem como as suas principais fontes em uma amostra de 18 dos principais institutos de pesquisa da área de TICs no Brasil. Tais institutos são organizações que operam à base de fornecimento de serviços para a indústria de TIC, serviços estes intensivos em conhecimento técnico-científico. Por isso, tais institutos foram examinados aqui como OSICs. Embora se argumenta sobre a importância da indústria de TIC e, particularmente, sobre o papel das OSICs na economia baseada em serviços e na competição globalizada à base de conhecimento tecnológico (ver, por exemplo, Pavitt, 2002; Miles, 2003), a literatura existente ainda é escassa de estudos que examinem, de maneira sistemática, a gestão de capacidades tecnológicas, especialmente em OSICs que operam em economias em desenvolvimento, como é o caso do Brasil.

De outro lado, a presença e a qualidade das OSICs em países em desenvolvimento têm sido interpretada como condiçōes-chave para a atração e instalação de atividades de P\&D de empresas transnacionais nesses países (The Economist Intelligence Unit, 2004; UNCTAD, 2005). Porém, muito pouco tem sido estudado em termos dos tipos e níveis de capacidade tecnológica em OSICs localizadas em países em desenvolvimento, especialmente no Brasil. $\mathrm{Ou}$ seja, muito embora as OSICs sejam fortemente valorizadas nos discursos governamentais, empresariais e de agências de desenvolvimento, muito pouco tem sido feito em termos de um escrutínio empírico dos tipos e níveis de capacidades tecnológicas existentes e das principais fontes dessas capacidades. Por isso, o estudo subjacente a este artigo objetivou contribuir para avançar no entendimento relativo à capacidade para realizar atividades tecnológicas inovadoras em OSICs que operam em um contexto de uma economia de industrialização recente. As evidências encontradas neste estudo sugerem que:

(1) Há uma diversidade de tipos e níveis de capacidades tecnológicas nos institutos da amostra. Porém, a maioria dos institutos alcançou o Nível 4 como nível máximo de capacidade para as quatro funções examinadas. Não obstante, foram encontrados 12 institutos em Nível 5 de capacidade para realizar atividades de engenharia de software, sete institutos em 
Nível 5 de capacidade para gerar produtos (serviços) e soluçōes, dois institutos em Nível 5 para atividades de gestão de projetos. Vale reiterar que foi encontrado um instituto em Nível 6 para engenharia de software e para produtos e soluções. De outro lado, nenhum instituto está confinado apenas aos níveis de capacidades tecnológicas rotineiras. Porém, é preocupante a discrepância entre o número de institutos que alcançaram Nível 5 em engenharia de software (12 ou 66,6\%) e os que alcançaram esse mesmo nível de capacidade para gestão de projetos (2 ou $11,1 \%)$ - ver Tabela 5 .

(2) Por sua vez, foram encontradas diversas fontes utilizadas pelos institutos para construir tais capacidades tecnológicas. Tais fontes referem-se aos processos intra-organizacionais de aprendizagem e as ligaçôes com demais organizações do sistema de inovação. As evidências relativas a essas fontes de informações permitem ampliar o nosso conhecimento sobre como os institutos constroem (ou não) suas capacidades tecnológicas. Porém, foi encontrada baixa incidência de práticas de codificação de conhecimento técnico, assim como baixa incidência de interações entre os institutos.

(3) As evidências deste trabalho sugerem que os argumentos que atribuem ao "sistema de inovação brasileiro" um papel passivo em termos de aprendizagem tecnológica e capacidade inovadora (Viotti, 1997, 2000) assim como classificação do Brasil no Relatório Global de Tecnologia da Informação (edição 2005-2006), 52 a posição, devem ser interpretados com cautela, pois carecem de fundamentação metodológica e empírica. Certas generalizaçôes, como esta que consta do relatório do WEF, que nem sempre refletem a realidade industrial diversificada do Brasil, podem deturpar decisóes de políticas públicas e de investimento empresarial.

(4) Por outro lado, de maneira similar ao que tem sido encontrado em empresas industriais manufatureiras (Dutrénit, 2000; Ariffin, 2000; Figueiredo, 2001, 2003), a gestão da inovação em organizações de serviços aqui estudadas também implica mudar e gerir bases diversas de conhecimento e distintas especialidades - capacidades ou competências para realizar atividades ou funçôes tecnológicas variadas. Essas capacidades ou bases de conhecimento não se refletem apenas em capital humano 
(expertise) e sistemas técnico-físicos (máquinas, software e banco de dados) nessas organizações. Parte substancial dessas capacidades tecnológicas está acumulada e armazenada nas rotinas, procedimentos, normas e valores dessas OSICs, Logo, as atividades de integração e de coordenação de distintas bases de conhecimento técnico-científico, entre diferentes áreas funcionais, torna-se tarefa crítica para a gestão dessas OSICs.

(5) Portanto, a gestão da inovação nessas organizações implica, de um lado, o desenvolvimento de uma visão ampliada de capacidade tecnológica por parte de seus gestores. De outro, implica um esforço contínuo de aprofundamento e renovação das capacidades tecnológicas inovadoras existentes (inovação contínua), mas também abandono de certas capacidades técnico-organizacionais (inovação descontínua), a fim de responder, de maneira criativa, às demandas crescentes de serviços caracterizados cada vez mais pela intensidade de conhecimento técnico-científicos e multiplicidade de bases de conhecimento ou saber - como é o caso de software para a indústria de TIC e para as crescentes necessidades de conectividade em certas indústrias como a de eletrodomésticos (Ferigotti \& Figueiredo, 2005).

(6) No caso específico das OSICs aqui examinadas, isto é particularmente importante quando se considera um cenário pós-Lei de Informática. As evidências aqui mostram que os institutos que alcançaram Níveis 5 e 6 de capacidade tecnológica inovadora têm adotado práticas de renovação contínua de suas bases de conhecimento. Esses institutos parecem estar construindo uma base organizacional sofisticada para apoiar futuras atividades tecnológicas complexas. Isto, por sua vez, implica uma gestão deliberada, sistemática e competente das diversas fontes de capacidade tecnológica.

(7) Mais especificamente, significa gerir diariamente uma variedade de processos internos de aprendizagem e, em paralelo, gerir uma extensa variedade de ligações de saber com diversos componentes do sistema de inovação, tanto em nível nacional como internacional. Este tipo de gestão da inovação foi encontrado nos institutos aqui estudados que alcançaram os níveis mais inovadores de capacidades tecnológicas para atividades diversas como engenharia de software, gestão de projetos, produtos e soluçôes e de ferramentas e processos (conforme a métrica na Tabela 1). 
(8) Porém, além dos esforços intra-organizacionais, os esforços de política governamental jogam um papel relevante no processo de fortalecimento e renovação das capacidades tecnológicas nas OSICs aqui estudadas. As estratégias governamentais de suporte à inovação industrial são cada vez mais necessárias para apoiar o desenvolvimento tecnológico em diversos setores industriais, particularmente no caso das OSICs do setor das TIC. Tais estratégias podem envolver, por exemplo:

(i) a constante revisão e atualização dos currículos universitários. Isto contribuiria para uma oferta mais qualificada de recursos humanos para as diversas OSICs, suas empresas parceiras e clientes e para a indústria de TIC no País;

(ii) esforços voltados para a aceleração do alcance de níveis mais avançados de capacidades tecnológicas inovadoras, não apenas nos institutos de TIC mais representativos no Brasil, como estes aqui estudados, mas também os de médio e pequeno portes. Isso possibilitaria a ampliação da massa crítica nacional de OSICs para atrair investimentos produtivos na indústria de TICs no Brasil;

(iii) no entanto, há questôes estratégicas que merecem reflexão e ação: Quantas OSICs de TIC em Nível de 6 de capacidade tecnológica o Brasil precisa? Em quanto tempo espera-se aumentar o número de OSICs em Níveis de 4 e 5 de capacidade para certas funções tecnológicas? Para que são necessárias OSICs em Nível 6?

(iv) estímulos transcendem a mera manutenção da Lei de Informática (mecanismo estático) e seus intricados mecanismos burocráticos de controle das atividades dos institutos de pesquisa por ela beneficiados. Clarificação e simplificação da moldura institucional ("regras do jogo") são necessárias para possibilitar e acelerar a tomada de decisão de empresas e de outros potenciais investidores (por exemplo, redução de barreiras burocráticas que podem retardar investimentos e uma ampla revisão do Plano Nacional de Microeletrônica);

$(v)$ em termos mais dinâmicos, tais esforços deveriam envolver, por exemplo, a avaliação periódica (a cada dois anos) do desenvolvimento de tipos e níveis de capacidade tecnológica em diversas OSICs. Também deveriam envolver metas realistas de desenvolvimento capacidades 
tecnológicas de longo prazo para esse tipo de OSICs. Esforços de avaliação sistemática, contínua e construtiva de organizações do sistema de inovação suportadas por regimes fiscais é prática comum em países como Finlândia e Malásia.

A diversidade de mecanismos necessários para a construção e sustentação das capacidades tecnológicas nos fornece, de um lado, uma noção prática dos reais desafios subjacentes à gestão de OSICs em um mercado em crescente globalização. De outro, as evidências neste estudo sugerem emergência de uma resposta positiva de um conjunto de organizações do sistema de inovação no Brasil ao regime de incentivos fiscais para a inovação, criado no início dos anos 1990 (a nova Lei de Informática). Essa resposta, que emerge de dentro de varias organizações relacionadas ao setor de TICs na economia, não apenas difere de situações anteriores no Brasil, como também pode contribuir para concretizar avanços significativos em termos de capacidade inovadora e competitiva dessa indústria no País.

Por isso, esse fato merece cuidadosa atenção e rápido processo decisório (em termos de prioridades de ação e de alocação de recursos) de todos os envolvidos com o desenho e implementação de ações voltadas para o fortalecimento da competitividade internacional do setor das TICs no Brasil. Muito embora o Brasil (e a América Latina) tenha perdido a "janela de oportunidade" da microeletrônica durante os anos 1980, as evidências de alguns dos efeitos positivos gerados pela nova Lei de Informática até aqui, algumas geradas por meio deste estudo, parecem apontar para uma nova oportunidade tecnológica (Freeman \& Perez, 1988) que abre para o Brasil neste momento. Porém, esta nova "janela” não deve ser desperdiçada.

A despeito das limitaçôes deste estudo, comentadas ao longo do texto, abordagens pragmáticas, como a adotada aqui, para o estudo de capacidade tecnológica e inovação em OSICs são necessárias para orientar e apoiar as estratégias de inovação em nível corporativo e governamental neste campo. Caso contrário, os argumentos sobre importância das OSICs do setor de TICs não passarão de mera retórica. 


\section{Referências bibliográficas}

Amsden, A.H.; Tschang, F.T., "A new approach to assessing the technological complexity of different categories of R\&D (with examples from Singapore)", Research Policy, v.31, p.553-572, 2003.

Ariffin, N., The Internationalisation of Innovative Capabilities: the Malaysian electronics industry, Thesis SPRU, Brighton, University of Sussex, 2000.

Ariffin, N.; Bell, M., "Patterns of Subsidiary-parent Linkages and Technological Capability Building in Electronics TNC Subsidiaries in Malaysia”, in Jomo K. S.; Felker, G. (orgs.), Industrial Technology Development in Malaysia, p.150190, Routledge, 1996.

; Figueiredo P.N., "Internationalisation of Innovative Capabilities: counter-evidence from the electronics industry in Malaysia and Brazil", Oxford Development Studies, v.32, n.4, p.559-583, 2004.

Baark, E., Routines and Innovations in Engineering Consultancy Services, Kowloon, Hong Kong, 2001.

Baptista, M., "The Consumer Electronics Industry in Brazil: current situation and outlook", in Clélia Piragibe (coord.), Electronics industry in Brazil: current status, perspectives and policy options. Brazil, Center of Studies in Scientific and Technological Policy, Ministry of Science and Technology, November, 1988.

Barras, R., "Towards a theory of innovation in services", Research Policy, v.15, n.4, p.161-173, 1986.

Baskerville, R.; Pries-Heje, J. "Knowledge capability and maturity in software management", Database for Advances in Information Systems, v.30, n.2, p.26, 1999.

Bell, M., "Integrating R\&D With Industrial Production \& Technical Change: Strengthening Linkages \& Changing Structures", Science Policy Research Unit, n.4, 1993.

Bell, M.; Albu, M., "Knowledge systems and technological dynamism in industrial clusters in developing countries", World Development, v.27, n.9, p.1.715$1.734,1999$.

Bell, M.; Pavitt, K., "Technological accumulation and industrial growth: contrasts between developed and developing countries", Industrial and Corporate Change, v.2, n.2, p.157-211, 1993. 
, "The development of technological capabilities". in Haque, I.U., Trade, Technology and International Competitiveness, Washington: The World Bank, p.69-101, 1995.

Campos, A.L.S.; Teixeira, A.G., "Política Industrial e Capacitação Tecnológica: Análise da Dimensão Explícita da Política Nacional de Informática (19911998)", Leituras de Economia Política, v.10, 2004.

Carvalho, R., Why the Market reserve is not enough: the diffusion of industrial automation technology in Brazilian process industries, in Schmitz, H; Cassiolato, J., Hi-tech for industrial development: lessons from the Brazilian experience in electronics and automation, Routledge, 1992.

Castells, M., The information age: economy, society and culture, v.1-3, Oxford: Blackwell Publishers, 1996.

Cassiolato, J., The user-producer connection in hi-tech: a case study of Banking Automation in Brazil. in Schmitz, H.; Cassiolato, J., High-tech for industrial development: lessons from the Brazilian Experience in Electronics and Automation, Routledge, 1992.

Cavalcanti, P.F.; Rossi, J.L., "New evidence from Brazil on trade liberalization and productivity growth", International Economic Review, v.44, n.4, 2003.

Chenery, H.B.; Robinson, S.; Syrquin, M., Industrialization and Growth: A Comparative Study, Nova York: Oxford University Press, 1986.

Cimoli, M.; Katz, J., "Structural reforms, technological gaps and economic development: a Latin American perspective", Industrial and Corporate Change, v.12, n.2, p.387-407, 2003.

Cooper, C.; Kaplinsky, R., Technology and development in the Third industrial revolution, Londres: Frank Cass, 1989.

Dosi, G., "Sources, procedures, and microeconomic effects of innovation", Journal of Economic Literature, v.26, set., p.1.120-1.171, 1988.

Dutrénit, G., Learning and knowledge management in the firm: from knowledge accumulation to strategic capabilities. Cheltenham, UK; Northampton, MA, USA: Edward Elgar Publishing, 2000.

Economist Intelligence Unit, "Scattering the seeds of invention: The globalisation of research and development". The Economist, 2004.

Edquist, C., Systems of Innovation: Technologies, Institutions, Organisations, Londres: Printer, 1997. 
Ernest, D.; O'Connor, D., Technology and global competition: the Challenge for Newly Industrialising Countries, OECD Development Centre, 1989.

Ethiraj, S.K.; Kale, P.; Krishnan, M.S.; Singh, J.V., "Where do capabilities come from and how do they matter? A study in the software services industry", Strategic Management Journal, v.26, p.25-45, 2005.

Fagerberg J.; Mowery D.C.; Nelson, R.R., The Oxford Handbook of Innovation, Oxford: University Press, 2006.

Ferigotti, C.; Figueiredo, P.N., "Managing learning in the refrigerator industry: Evidence from a firm-level study in Brazil", Innovation: management, policy \& practice, v.7, n.2-3, 2005.

Figueiredo, P.N., Technological learning and competitive performance, Cheltenham, UK \& Northampton, EUA: Edward Elgar, 2001.

, "Learning, capability accumulation and firms differences: evidence from latecomer steel", Industrial and Corporate Change, v.12, n.3, p. 607643, 2003.

, "Aprendizagem tecnológica e inovação industrial em economias emergentes: uma breve contribuição para o desenho e implementação de estudos empíricos e estratégias no Brasil", Revista Brasileira de Inovação, v.3, n.2, p. 323-362, $2004 a$.

, "Pesquisa empírica sobre aprendizagem tecnológica e inovação industrial: alguns aspectos práticos de desenho e implementação”, in Vieira, M.M.; Zouain, D.M., Pesquisa qualitativa em administração, Rio de Janeiro, Editora Fundação Getúlio Vargas, 2004b.

Figueiredo, P.N.; Vedovello, C. "Incubadora de inovação: que nova espécie é essa?", RAE Eletrônica, v.14, n.1, 2005.

Figueiredo, P.N.; Vedovello, C.; Marne, S.M.; Marins, L.M., "Research and technology institutes (RTIs) in a latecomer innovation system: evidence from the information and comunication technology (ICT) industry in Brazil", International Journal of Globalization and Technology , v.1, n.3-4, p.286-310, 2005.

Figueiredo, P.N.; Vedovello, C., Capacidade tecnológica industrial e sistema de inovação, Rio de Janeiro: Editora Fundação Getúlio Vargas, 2006.

Figueiredo, P.N., "Introduction to the special issue on firm-level learning and technological capability building in industrialising economies", International Journal of Technology Management, v.36, n.1-3, p.1-13, 2006. 
Figueiredo, P.N.; Marins, L.M., Globalização de Competências Tecnológicas Inovadoras no Contexto de industrialização Recente: Evidências de uma Amostra de Institutos de Pesquisa e Desenvolvimento (P\&D) em Tecnologias e Informação e Comunicação (TIC) no Brasil. Programa de Pesquisa em Aprendizagem Tecnológica e Inovação Industrial no Brasil, EBAPE-FGV, Relatório Final, Rio de Janeiro, p.295, 2005.

Freeman, C., The Economics of Industrial Innovation, 2.ed, Londres: Pinter, 1982. ; "The economics of technical change", Cambridge Journal of Economics, v.18, p.463-514, 1994.

Freeman, C.; Perez, C., "Structural crises of adjustment, business cycles and investment behaviour", in Dosi, G. et al., Technical Change and Economic Theory, Londres: Pinter Publishers, 1988.

Gaio, F.J., "Software strategies for developing countries: lessons from the international and Brazilian experience", in Schmitz, H.; Cassiolato, J., Hightech for industrial development - lessons from the Brazilian experinece in Electronics and Automation, Routledge, 1992.

Garcia, R.; Roselito, J.E., Critical evaluation of the "Informatics Law" and its reflexes on electronic complex, EUNIP Conference, nov., 2002.

Gann D.; Salter, A., "Innovation in Design, Engineering and Project Management Services", in: Tidd, J.; Hull, F. M., Service Innovation: Organizational Responses to Technological Opportunities \& Market Imperatives, Imperial College Press, v.9, p.301-320, 2003.

Gerschenkron, A., Economic backwardness in historical perspective, Cambridge, MA: Harvard University Press, 1962.

Hobday, M., Innovation in East Asia: The Challenge to Japan, Aldershot: Edward Elgar, 1995.

Katz, J., The limits of the prevailing orthodoxy: technology and education as restrictions to productivity growth and international competitiveness in Latin America. Proceedings of DRUID Summer Conference on Industrial Dynamics, Innovation and Development, Elsinore, Dinamarca, 14-16 jun., 2004.

"Market-oriented reforms, cycles of destruction and creation of production capacity and the building up of domestic technological capabilities", Cadernos EBAPE.BR, Edição Especial, Rio de Janeiro: FGV EBAPE, 2005. 
Kim, L., Imitation to Innovation. The Dynamics of Korea's Technological Learning, Boston, MA: Harvard Business School Press, 1997.

Kline, S.; Rosenberg, N., "An overview of innovation”, in Landau, R., The Positive Sum Strategy, Washington: National Academy Press, 1986.

Kuruvilla, S.; Erickson, C.L.; Hwang, A., "An assessment of the Singapore Skills development system: does it constitute a viable model for other developing countries?”, World Development, v.30, n.8, p.1.461-1.476, 2002.

Lall, S., Building Industrial Competitiveness in Developing Countries, Development Studies, 1990.

, "Technological capabilities and industrialization", World Development, v.20, n.2, p.165-86, 1992.

, "Competitiveness indices and developing countries: an economic evaluation of the Global Competitiveness Report”, World Development, v.29, n.9, p.1.501-1.525, 2001.

, Competitiveness, technology and skills, Cheltenham: Edward Elgar, 2001.

Leonard-Barton, D., Wellsprings of Knowledge: building and sustaining the sources of innovation, Boston, MA: Harvard-Business School Press, 1995.

Lundvall, B.A., "User-producer relationships, national systems of innovation and internationalisation" in Lundvall, B.A., National Systems of Innovation: Towards a Theory of Innovation and Interactive Learning, Pinter, Londres e Nova York: ed. N.A., p.45-94, 1992.

Marins, L.M., Globalização de competências tecnológicas inovadoras: evidências dos institutos de pesquisa e desenvolvimento em telecomunicações e tecnológica da informação no Brasil, Dissertação de Mestrado, Escola Brasileira de Administração Pública e de Empresas, FGV, Rio de Janeiro, 2005.

Mani, S., Coping with globalisation: an analysis of innovation capabilities in Brazilian telecommunications equipment industry. Discussion paper series. Maastricht: U.N. University, Intech, 2004.

MCT, Setor de tecnologias da informação: resultados da Lei 8.248/91, http:// www.mct.gov.br, 1998.

Miles, I., "Services and the Knowledge-based economy", in Tidd, J.; Hull, F.M., Service Innovation: Organizational Responses to Technological Opportunities \& Market Imperatives. Series on technology management, v.9, Imperial College Press, 2003. 
Miles, M.B.; Huberman, M.A., Qualitative data analysis: a source of new methods, Londres: Sage, 1984.

Miranda, E.C., Direção e Taxa (Velocidade) de Acumulação de Capacidades Tecnológicas: Evidências de uma Pequena Amostra de Empresas de Software no Rio de Janeiro e em São Paulo. Dissertação de Mestrado. Rio De Janeiro: EBAPE/Fundação Getúlio Vargas, 2005.

Mody, A.; Dahalman, C. "Performance and potential of information technology: an international perspective", World Development, v.20, n.12, Special Issue, 1992.

Mowery, D.; Ziedonis, A., "Numbers, quality and entry: How has the BayhDole Act affected US university patenting and licensing?”, in Jaffe, A.; Lerner, J.; Stern, S., Innovation Policy and Economy, v.1, NBER, Cambridge, MA: MIT Press, 2000.

Murphy, M.; Vickery, G., Strategic Business Services, Paris OECD, 1999.

Nelson, R.R., National systems of innovation: A comparative Study, Oxford Study: OUP, 1992.

Nelson, R.R.; Winter, S.G., An Evolutionary Theory of Economic Change, Cambridge, MA: Harvard University Press, 1982.

Patton, M.Q. Qualitative evaluation and research methods. 2.ed. Newbury Park, California: Sage, 1990.

Pavitt, K.; Steinmueller, W.E., "Technology in corporate strategy: change, continuity and the information revolution", in Pettigrew, A.; Thomas H.; Whittington, R. (orgs.), Handbook of Strategy and Management, Sage Publications, p.344-372, 2001.

, "Systems Integrators as "post-industrial" firms?", Science and Technology Policy Research, SPRU - Science and Technology Policy Research, 2002.

Penrose, E.T., The theory of the growth of the firm, Oxford: Basil Blackwell, 1959.

Saravia, E., Proceso de Privatización in Argentina y Brasil: Practicas Utilizadas paral el Ajuste de Personal y Consequencias en Materia de Trabajo y Desempeño Empresarial. Working Paper, Genebra: International Labour Organization (ILO), 1996.

Sutz, J.; Arocena, R., "Emerging neoperipheral structures and gardening policies" in Proceedings of the DRUID Summer Conference 2004 on Industrial Dynamics, Innovation and Development, Elsinore, Dinamarca, jun. 14-16, 2004. 
Suzigan, W.; Villela, A., Industrial Policy in Brazil, Campinas: UNICAMP/IE, 1997.

Szapiro, M.; Cassiolato, J., Telecommunications System of Innovation in Brazil: Development and Recent Challenges. The First Globelics Conference Innovation Systems and Development Strategies for the Third Millennium, Rio de Janeiro, 2003.

Tacla, C.L.; Figueiredo P.N., "The dynamics of technological learning inside the latecomer firm: evidence from the capital goods industry in Brazil", International Journal of Technology Management, v.36, n.1-3, p.62-90, 2006.

Teece, D.; Pisano, G., “The dynamic capabilities of firms: an introduction”, Industrial and Corporate Change, v.3, p.537-56, 1994.

Tigre, P.B., "Business strategies in the Brazilian electronics industry", in Clélia Piragibe, Electronics industry in Brazil: current status, perspectives and policy options. Brasil, Centro de Estudos em Política Científica e Tecnológica, MCT, 1988.

, “Liberalização e capacitação tecnológica: o caso da informática pósreserva de mercado no Brasil”. Texto para Discussão, Rio de Janeiro, IEI/ UFRJ, 1993.

Tidd, J.; Hull, F.M. Managing Service Innovation: Variations of best practice. in Tidd, J.; Hull, F.M., Service Innovation: Organizational Responses to Technological Opportunities \& Market Imperatives, Series on technology management, v.9, Imperial College Press, 2003.

UNCTAD, Occasional Note: UNCTAD survey on the internationalization of R\&D Current patterns and prospects on the internationalization of R\&D. United Nations, Nova York e Genebra, 2005.

Vedovello, C. Science Parks and the University-Industry Links: A Case Study of the Surrey Research Park. PhD Thesis, Brighton, UK: SPRU, University of Sussex, 1995.

"Perspectivas e limites da interação entre universidades e MPMEs de base tecnológica localizadas em incubadoras de empresas", Revista do BNDES, v.8, n.16, p.281-316, 2001.

Viotti, E.B., Passive and active national learning systems: A framework to understand technical change in late industrializing economies and some evidences from a comparative study of Brazil and South Korea. Unpublished PhD thesis. Nova York: The New School University, 1997 
Passive and active national learning systems: a framework to understand technical change in late industrializing economies and some evidences from a comparative study of Brazil and South Korea, $4^{\text {th }}$ International Conference on Technology Policy and Innovation, Curitiba, 28-31 ago., 2000.

Von Tunzelmann, G.N., "Technology and Industrial Progress: The Foundations of Economic Growth", Cheltenham: Edward Elgar, 1995.

World Economic Forum/Insead (2004-2005), The Global Information Technology Report, Lausanne, 2005.

World Economic Forum/Insead (2004-2005), The Global Information Technology Report. Lausanne, 2006. 